\title{
Development of an Overview Display to Allow Advanced Outage Control Center Management to Quickly Evaluate Outage Status
}

\author{
Shawn St. Germain \\ Jacques Hugo
}

September 2016

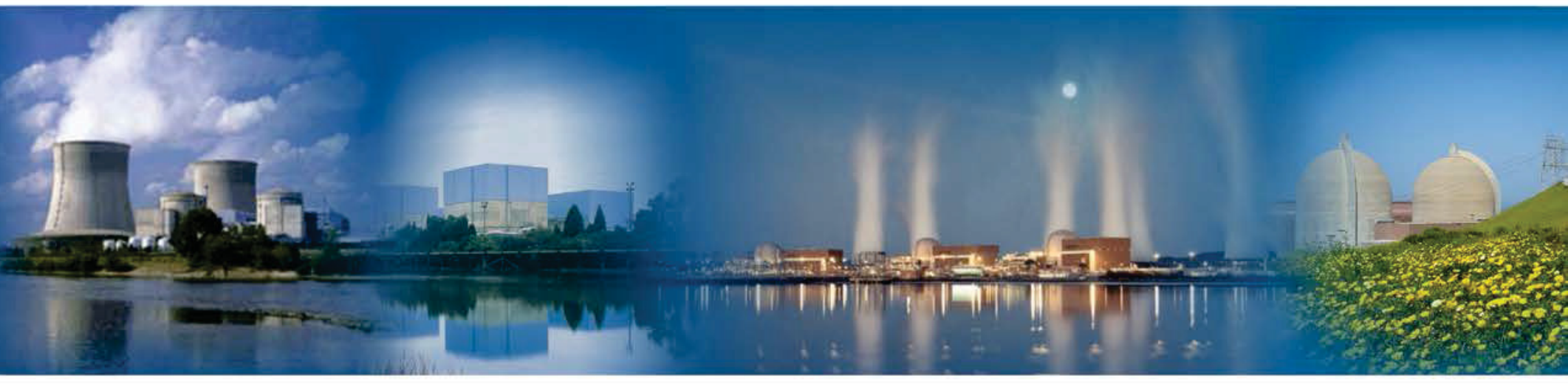

The INL is a U.S. Department of Energy National Laboratory operated by Battelle Energy Alliance 


\section{DISCLAIMER}

This information was prepared as an account of work sponsored by an agency of the U.S. Government. Neither the U.S. Government nor any agency thereof, nor any of their employees, makes any warranty, expressed or implied, or assumes any legal liability or responsibility for the accuracy, completeness, or usefulness, of any information, apparatus, product, or process disclosed, or represents that its use would not infringe privately owned rights. References herein to any specific commercial product, process, or service by trade name, trade mark, manufacturer, or otherwise, does not necessarily constitute or imply its endorsement, recommendation, or favoring by the U.S. Government or any agency thereof. The views and opinions of authors expressed herein do not necessarily state or reflect those of the U.S. Government or any agency thereof. 


\title{
Development of an Overview Display to Allow Advanced Outage Control Center Management to Quickly Evaluate Outage Status
}

\author{
Shawn St. Germain \\ Jacques Hugo
}

September 2016

\author{
Idaho National Laboratory \\ Idaho Falls, Idaho 83415 \\ http://www.inl.gov
}

Prepared under Work Package L-12N060305

Prepared for the

U.S. Department of Energy

Office of Nuclear Energy

Under DOE Idaho Operations Office

Contract DE-AC07-05ID14517 



\section{EXECUTIVE SUMMARY}

This research effort is a part of the Light Water Reactor Sustainability (LWRS) Program, which is a research and development (R\&D) program sponsored by the Department of Energy. The LWRS Program is performed in close collaboration with industry $R \& D$ programs that provide the technical foundations for licensing and managing the long-term, safe, and economical operation of current nuclear power plants (NPPs). The LWRS Program serves to help the United States (U.S.) nuclear industry adopt new technologies and engineering solutions that facilitate the continued safe operation of these NPPs and extension of their current operating licenses.

Refueling outages remain one of the largest opportunities for improving capacity factor and reducing costs available to commercial NPPs. Although the nuclear industry has made steady improvement in outage optimization, each day of a refueling outage still represents an opportunity to save millions of dollars and each day an outage extends past its planned end date represents millions of dollars that may have been spent unnecessarily. Reducing planned outage duration or preventing outage extensions requires careful management of the outage schedule as well as constant oversight and monitoring of work completion during the outage execution. Management of the critical path is generally well understood and handled quite well in most commercial NPPs. Techniques for reducing the critical path are shared during benchmarking activities and with support of the major vendors. During a typical outage, however, there are typically more than 10,000 activities on the schedule that are not on the critical path. These noncritical path activities, or bulk work activities, if not managed correctly may cause outage delays beyond the critical path. Management of bulk work currently relies on using lists of activities sorted into various schemes in efforts to provide managers with a clear picture of current progress. A typical tool currently used to monitor bulk work performance is a burn-down curve, where total remaining activities are plotted against the baseline schedule to track bulk work completion progress. While these tools are useful, there is still considerable uncertainty during a typical outage that bulk work progress is adequate and therefore a lot of management time is spent analyzing the situation on a daily basis.

This report describes recent advances made in developing a framework for the design of visual outage information presentation, as well as an overview of the scientific principles that informed the development of the visualizations. Visual presentation of information can assist outage managers in more easily understanding the true status of bulk work completion. Additionally, this report describes how incorporating historical outage performance into visual displays may allow a more precise measure of current performance than the burn-down curves currently used. To test the use of visual outage information presentation, an outage management dashboard software application was created. This dashboard is intended to present all the critical information an outage manager would need to understand the current status of a refueling outage. The dashboard presents the critical path, bulk work performance, key performance indicators, outage milestones and metrics relating current performance to historical performance. Additionally, the dashboard includes data analysis tools to allow outage managers to drill down into the underlying data to understand the drivers of the indicators. 


\section{ACKNOWLEDGMENTS}

The Advanced Outage Control Center research team would like to acknowledge the efforts of the following individuals and organizations that made this research possible: Todd Horton, Bruce Gordon, Carlos Williams, and members of the Arizona Public Services Palo Verde Nuclear Generating Station staff for hosting and participating in the research activities. 


\section{CONTENTS}

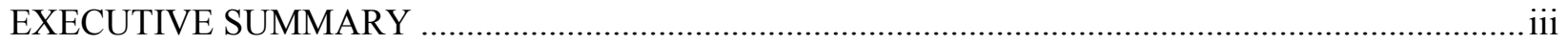

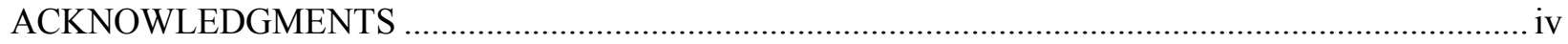

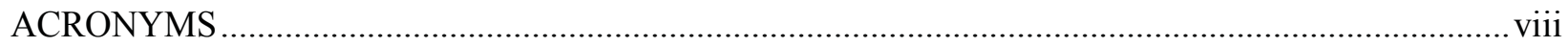

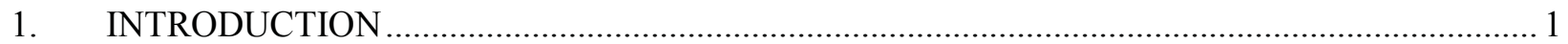

2. HUMAN FACTORS PRINCIPLES IN DATA VISUALIZATION ............................................ 2

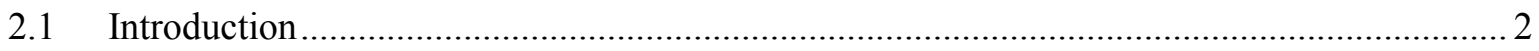

2.2 General Principles Governing Information Displays in the OCC ...................................... 2

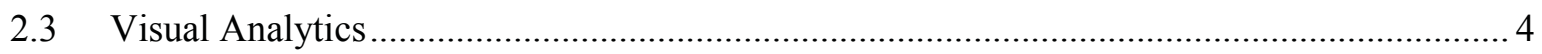

2.4 Meaning, Comprehension and Mental Models in the Workplace......................................... 4

2.4.1 What is "meaning" ........................................................................................... 4

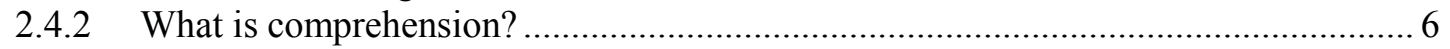

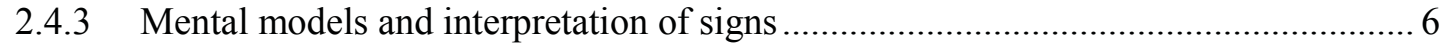

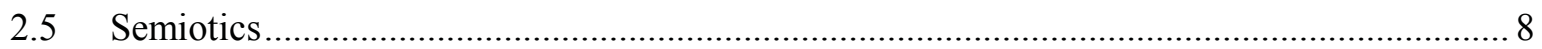

2.5.1 Semiotics in Linguistics .............................................................. 8

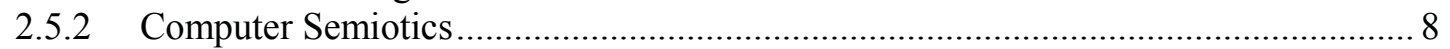

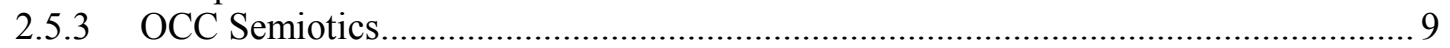

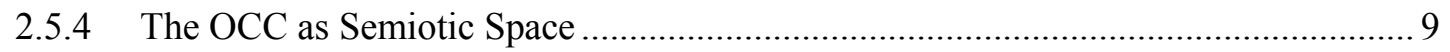

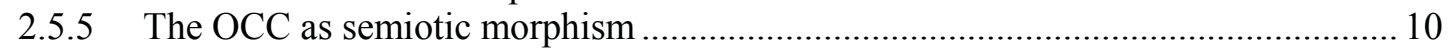

2.5.6 A formal model for dashboard design............................................................... 10

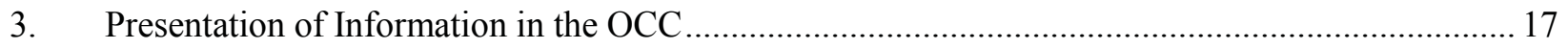

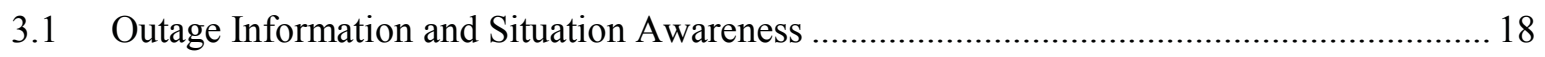

3.2 The Need for an Integrated Information Display ............................................................ 20

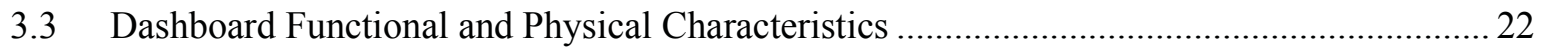

3.4 Development of a Prototype Outage Dashboard................................................................. 24

3.5 Application of the PSF to the Palo Verde Dashboard ............................................................ 28

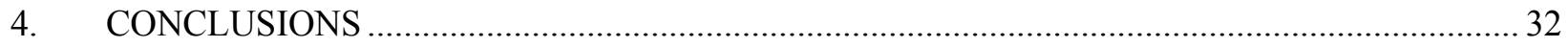

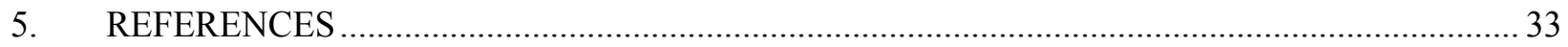

\section{FIGURES}

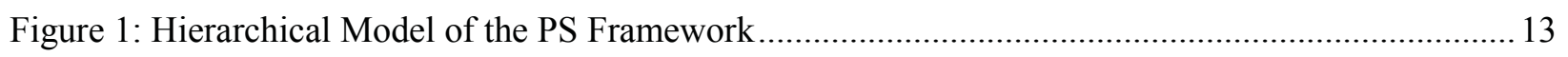

Figure 2: Outage Information Dashboard Prototype (Activity view) ....................................................2 24

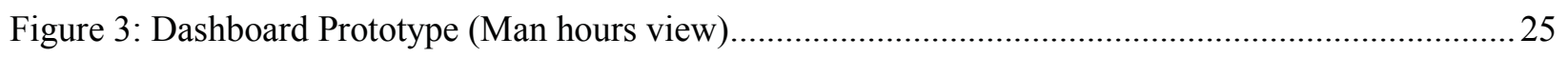




\section{ACRONYMS}

AOCC Advanced Outage Control Center

DS discrete signs

FI figurative screen image

HFE human factors engineering

HSI human-system interface

INL Idaho National Laboratory

KPI key performance indicator

LWRS Light Water Reactor Sustainability

NPP nuclear power plant

OCC Outage Control Center

PS Physical Interaction System

PSF paradigmatic-syntagmatic framework

PVNGS Palo Verde Nuclear Generating Station

QC quality control

$\mathrm{R} \& \mathrm{D} \quad$ research and development

SM subject matter

SO spatial organization

U.S. United States 


\section{INTRODUCTION}

This research effort is a part of the Light Water Reactor Sustainability (LWRS) Program, which is a research and development program sponsored by the Department of Energy. The LWRS Program is performed in close collaboration with industry research and development programs that provide the technical foundations for licensing and managing the long-term, safe, and economical operation of current nuclear power plants (NPPs). The LWRS Program serves to help the United States nuclear industry adopt new technologies and engineering solutions that facilitate the continued safe operation of these NPPs and extension of the current operating licenses. One major area selected for research into enabling capability is in outage safety and efficiency.

A pilot project in the LWRS program, "Advanced Outage Control Center" (AOCC), is a multi-year effort targeted at NPP outage improvement. The primary purpose of this pilot project is to improve management of NPP outages through the development of an AOCC that is specifically designed to maximize the usefulness of communication and collaboration technologies for outage coordination and problem resolution activities.

Refueling outages remain one largest opportunities for improving capacity factor and reducing costs available to commercial NPPs. Although the nuclear industry has made steady improvement in outage optimization, each day of a refueling outage still represents an opportunity to save millions of dollars and each day an outage extends past its planned end date represents millions of dollars that may have been spent unnecessarily. Reducing planned outage duration or preventing outage extensions requires careful management of the outage schedule and constant oversight and monitoring of work completion during the outage execution. Management of the critical path is generally well understood and handled quite well in most commercial NPPs. Techniques for reducing the critical path are shared during benchmarking activities and with support of the major vendors. During a typical outage, however, there are typically more than 10,000 activities on the schedule that are not on the critical path. These non-critical path activities, or bulk work activities, if not managed correctly may cause outage delays beyond the critical path. Management of bulk work currently relies on using lists of activities sorted in various schemes to try and allow managers a clear picture of current progress. A typical tool currently used to monitor bulk work performance is a burn-down curve, where total remaining activities are plotted against the baseline schedule to track bulk work completion progress. While these tools are useful, there is still considerable uncertainty during a typical outage that bulk work progress is adequate and therefore a lot of management time is spent analyzing the situation on a daily basis.

Previous AOCC pilot project reports have provided information on outage control center (OCC) physical design, technology tools for improving emergent issue resolution, technologies and techniques for making outage information visible and sharable and new ways of displaying schedule information to take advantage of capabilities enabled by the use electronic work packages. This report focuses on tools that utilize technology to improve the outage manager's understanding of the true outage status. The primary tool described in this report is in the form of an interactive dashboard with built in data analysis capabilities. The dashboard takes advantage of data visualization techniques that allow the human brain to process information more efficiently when presented in different forms. The dashboard also incorporates historical performance data to help predict current performance. This new dashboard concept not only presents information, but also attempts to predict the completion of the current outage using data analysis of the current schedule and historical performance of the NPP. 


\section{HUMAN FACTORS PRINCIPLES IN DATA VISUALIZATION 2.1 Introduction}

As described in previous milestone reports, formal human factors engineering (HFE) methodologies and principles will be applied to the design of next generation OCCs. An important part of this humancentered approach is the judicious introduction of selected technology tools, which aims to assist the outage staff, and optimize outage staffing. However, this strategy is incomplete and will be ineffective without even more attention to the way outage information is communicated in the OCC. This requires an analytical approach to the display of outage information to ensure that cognitive as well as physical ergonomic challenges will be eliminated.

There is little argument about the complexity of OCC data; therefore, it is necessary to be able to analyze and interpret all of this data to improve the performance of the OCC. This becomes even more critical as more advanced technology, processes and functions are incorporated in the OCC, as part of the transformation to an "advanced outage control center". This AOCC transformation leads to the emergence of the "big data" challenge - extremely large data sets that need to be analyzed computationally to reveal patterns, trends, and associations, especially as it relates to human interaction with such data and the responses required. Big data is not characterized simply as the sheer quantity of data, but also the complexities and hidden relationships between data points.

The analysis of complex data requires a specialized process that conventional statistical methods and business intelligence applications cannot handle. In the evolving AOCC, this process will seek to uncover hidden patterns in complex data that can then be used to make better and quicker decisions. Part of this will aim to analyze and leverage past performance to improve overall outage efficiency and performance.

However, improved efficiency comes not only from the results of complex data analysis. The results must be transformed into information, which in turn is needed to build knowledge. Making sense of AOCC data relies almost entirely upon prior knowledge and experience. Unfortunately for much of the nuclear industry, there will soon be a large loss of knowledge and experience as senior staff retire and are replaced by younger, less experienced staff. The only coping mechanism available to team members in perceiving and interpreting information is their own cognitive abilities. Although it is true that graphical presentation of information is often better than words or numbers, simply presenting raw data as graphs, as is usually the case at present, does very little to reduce the cognitive burden. Much of this burden could be reduced by applying big data analytical "pre-processing" techniques before displaying the data. This calls for two scientific method; Visual Analytics, coupled with Semiotics, which will be explained in the following sections

\subsection{General Principles Governing Information Displays in the OCC}

Visual displays are an important part of maintaining staff alignment, both for staff assigned to the OCC and staff that visit the OCC to interface with the assigned staff. The type and quantity of information displayed in the OCC will depend on the number and makeup of staff assigned to the OCC, physical dimensions of the OCC, desk configuration, and physical availability to place displays in the OCC (especially wall space in the OCC). Recent experience at the OCC of a number of utilities has indicated that well-designed outage information displays visible to all staff at all times are very likely to improve situation awareness and general performance during the outage.

In the 2015 milestone report INL/EXT-15-36489, St. Germain et al. (2015) explained how displays can be characterized in human factors terms as "human-made artifacts designed to support perception of relevant system variables and facilitate further processing of that information." Every information or operational display, whether in the control room or the OCC, must be designed to support a particular task, or set of tasks. This includes functions integral to the display, such as navigation, controlling, 
decision-making, learning, or communication. It is essential that the display and its functions must be matched to the mental model, perceptual capabilities, and understanding of the users and enable them to process whatever information a system generates and displays.

The milestone report also described Wickens' (2004) 13 principles of display design. These principles are repeated here for easy reference:

\section{- Perceptual Principles}

Make displays legible (or audible). A display's legibility is critical and necessary to design a usable display. If the characters or objects displayed are not discernible, then the operator cannot effectively make use of them.

Avoid absolute judgment limits. Do not ask the user to determine the level of a variable on the basis of a single sensory variable (e.g., color, size, and loudness). These sensory variables can contain many possible levels.

Top-down processing. Signals are likely perceived and interpreted in accordance with what is expected based on a user's experience. If a signal is presented contrary to the user's expectation, more physical evidence of that signal may need to be presented to assure that it is understood correctly.

Redundancy gain. If a signal is presented more than once, it is more likely that it will be understood correctly. This can be done by presenting the signal in alternative physical forms (e.g., color and shape and voice and print), as redundancy does not imply repetition. A traffic light is a good example of redundancy, as color and position are redundant.

Similarity causes confusion: Use discriminable elements. Signals that appear to be similar will likely be confused. The ratio of similar features to different features causes signals to be similar. For example, A423B9 is more similar to A423B8 than 92 is to 93 . Unnecessary similar features should be removed and dissimilar features should be highlighted.

\section{- Mental Model Principles}

Principle of pictorial realism. A display should look like the variable that it represents (e.g., high temperature on a thermometer shown as a higher vertical level). If there are multiple elements, they can be configured in a manner that looks like it would in the represented environment.

Principle of the moving part. Moving elements should move in a pattern and direction compatible with the user's mental model of how it actually moves in the system. For example, the moving element on an altimeter should move upward with increasing altitude.

\section{- Principles Based on Attention}

Minimizing information access cost. When the user's attention is diverted from one location to another to access necessary information, there is an associated cost in time or effort. A display design should minimize this cost by allowing frequently accessed sources to be located at the nearest possible position. However, adequate legibility should not be sacrificed to reduce this cost.

Proximity compatibility principle. Divided attention between two information sources may be necessary to complete one task. These sources must be mentally integrated and are defined to have close mental proximity. Information access costs should be low, which can be achieved in many ways (e.g., proximity, linkage by common colors, patterns, and shapes). However, close display proximity can be harmful by causing too much clutter.

Principle of multiple resources. A user can more easily process information across different resources. For example, visual and auditory information can be presented simultaneously rather than presenting all visual or all auditory information.

\section{- Memory Principles}


Replace memory with visual information: knowledge in the world. A user should not need to retain important information solely in working memory or retrieve it from long-term memory. A menu, checklist, or another display can aid the user by easing the use of his/her memory. However, the use of memory may sometimes benefit the user by eliminating the need to reference some type of knowledge in the world (e.g., an expert computer operator would rather use direct commands from memory than refer to a manual). The use of knowledge in a user's head and knowledge in the world must be balanced for an effective design.

Principle of predictive aiding. Proactive actions are usually more effective than reactive actions. A display should attempt to eliminate resource-demanding cognitive tasks and replace them with simpler perceptual tasks to reduce the use of the user's mental resources. This will allow the user to not only focus on current conditions, but also think about possible future conditions. An example of a predictive aid is a road sign displaying the distance to a certain destination.

Principle of consistency. Old habits from other displays will easily transfer to support processing of new displays if they are designed consistently. A user's long-term memory will trigger actions that are expected to be appropriate. A design must accept this fact and use consistency among different displays.

These principles are regarded as universally valid and can thus form the foundation of the multidisciplinary design approach described in this report.

\subsection{Visual Analytics}

Visual analytics is a multi-disciplinary field that involves multiple processes and a wide variety of application areas. An early definition was "the science of analytical reasoning facilitated by interactive human-machine interfaces." A more specific definition would be: "Visual analytics combines automated analysis techniques with interactive visualizations for an effective understanding, reasoning and decision making on the basis of very large and complex datasets". Visual analytics is different from 'standard' approaches to analysis. It is based on the assumption that interactive visual representations can amplify human natural capabilities for detecting patterns, establishing links, and making inferences (Keim et al., 2010).

In practice, visual analytics aims to create of tools and techniques to enable people to synthesize information and derive insight from large amounts of dynamic, ambiguous, and often conflicting data. Coupled with this is the desired ability to detect the expected and discover the unexpected. This requires timely, defensible, and understandable assessments of data, and the means to communicate these assessment effectively for action.

The Visual Analytics method combines information visualization techniques with data analysis and computational transformation techniques, which support analytic reasoning, and thus the sense-making process. A typical and well-known application domain is emergency management, where the techniques can help determine the on-going progress of an emergency and identify the next countermeasures (e.g., construction of physical countermeasures or evacuation of the population) that must be taken to limit the damage. Such scenarios can include natural or meteorological catastrophes like flood or waves, volcanoes, storm, fire or epidemic growth of diseases, but also human-made technological catastrophes like industrial accidents, transport accidents or pollution. (Keim et al., 2010).

\subsection{Meaning, Comprehension and Mental Models in the Workplace}

\subsubsection{What is "meaning"}

Meaning can be described as the "...system of mental representations of an object or phenomenon, its properties and associations with other objects and/or phenomena. In the consciousness of an individual, meaning is reflected in the form of sensory information, images and concepts." (Bedny \& Korwowsky, 2004). Acquiring meaning from any visual display provides not only orientation in a situation, but also 
regulates the executive actions of the operator. However, we know that meaning is neither constant nor consistent and is influenced by context as well as an individual's frame of reference and experience. The "meaning" of objects has a situational character and is thus determined through the relationships between action and situation and may easily change when the situation changes. Because situations can persist for a long time, meaning can become "convention" and such conventions can become deeply embedded in language, culture and even operations, procedures, and policies. Even when the situation changes, such conventions can be so ingrained that they are extremely difficult to change, with the result that the original intended meaning no longer has any relevance.

Meaning in a display or a user interface can be either denotative or connotative:

- Denotation is the explicit or direct meaning of a word or phrase. In displays (like dashboards, user interfaces, or film) it is quite simply the visual expression of the objective semantic content of the represented object. When the designer makes a selection within paradigmatic variants, thereby assigning meaning to empty forms, the image possesses denotative meaning to the extent that the observer (operator, manager, engineer, etc.) recognizes it as a meaningful object.

- The Connotation of a word or phrase is the associated or secondary meaning, which could be negative or positive. In displays it results when the denotative relationship between signifier and signified serves as a means of expression for a second system, namely the connotative meaning. Connotative meaning is not objective even if the meaning so inferred conforms to the conventional meaning of the sign (which may be influenced by popular conventions anyway).

Connotative meaning is thus assigned by the observer and is not inherent in the object. However, connotative meaning is also context-dependent and the observer may be guided (for example through learning and association) to assign a specific connotation from among various possible meanings to an object. Unlike with denotative icons, it is only through indexical signs that the image can succeed in concretizing abstract concepts (see the definition of "index" in section 2.5.3). For example, the moving pointer of a gauge, or the shape of a trend graph, is an indexical sign that indicates change of a specific parameter over time. The representation of a temperature gauge as an indexical sign of heat would not in itself be regarded as a visual metaphor of the concept heat, but rather the visual representation of a heat gauge within the specific context of a single process control display or a series of displays. In this regard we would thus refer to this representational modality as a metaphor carrier and the whole context of the user interface as the framework. The metaphorical representation then serves not only as an iconic, denotative representation of something, but as a concretization of an abstract concept. The image of the gauge thus acquires a new value that belongs to something else.

In environments like the OCC or the control room where one would like to ensure that meaning is as objective as possible in order to avoid ambiguity and thus human error, it is important to remember, as indicated before, that meaning is influenced by uncertainty or conditions that interfere with accurate communication of concepts. Rogovin (1973, cited in Bedny \& Karwowski, 2004. p. 5) stated that there are four kinds of uncertainty:

1. Perceptual uncertainty: where low intensity or poor clarity of visual stimuli prevent operators from perceiving the sign accurately. This occurs for example with poor lighting in the work environment, low resolution, low contrast between object foreground and background, or symbols, icons and text that are too small for a given viewing distance.

2. Representational uncertainty: this occurs when there is no one-to-one connection between representation and symbol, for example when the symbol is a mere arbitrary embellishment on the user interface and it is not certain if it is meant to refer to something. This is sometimes called "gratuitous graphics", or "screen junk" (Tufte, 2001; Hugo and Gertman, 2013). 
3. Semantic uncertainty: this occurs when there is no one-to-one relationship between sign and meaning, for example the use of arbitrary symbols or icons for system functions, or more than one meaning for the same symbol.

4. Conceptual uncertainty: this refers to ill-defined problems, processes or procedures, for example where an operator can observe all objects in the interface, but does not know how to use them to perform a function.

In the design process, one must consider how the process of semiosis (that is, "sense-making") accounts for the extraction of the designer's "intended meaning" from the display. It is important to note that, in spite of earlier references to the "semantic content" of a sign, it does not have an inherent meaning. However, signs like gauges, graphs or text clearly have intended meaning assigned to them by the designer. This meaning could be conveyed in various ways - the most obvious way is labelling the sign, but context and relationship (for example proximity to other symbols or images) may also help to convey the intended meaning. In spite of these various methods, there is still no guarantee that the user will "get" the intended meaning, because many factors can inhibit effective communication: past experience, learning, prejudice, visual literacy, interruptions and distractions, environmental interference (e.g., noise or bright lights) etc.

\subsubsection{What is comprehension?}

Comprehension and meaning are closely related, but are the results of different processes. Comprehension is the result of "getting" the meaning of an object through a process of analyzing objects from different perspectives as well finding the relationships to other objects. For example, one of the important tasks of an operator in a control room is diagnosing the condition of the plant and faults that may occur. The word "diagnosis" itself suggests the nature of the cognitive process involved: "dia" means "through" and "gnosis" means "knowledge". "Diagnostic" thus literally means "understanding in depth" which explains how comprehension is accompanied by both a conscious and subconscious search for meaning, which can also be described as a process of semantic categorization. According to Brodesky (1998, cited in Bedny \& Karwowski, 2004) people develop "artificial semiotic strategies" for extracting meaning from a situation. This would correspond to the operator's learned or instinctive diagnostic behavior when trying to understand a condition.

Comprehension also involves the substitution of real objects by sign systems, each of which requires a specific system of actions and operations. The sign thus begins to serve the function of the real object or activity. However, words and pictures have imprecise meanings and vary in different situations. Meaning is also affected by associations with many other words and images. (Sheridan, 2002)

\subsubsection{Mental models and interpretation of signs}

A mental model is an individual's internal representation of how a system operates and how it is structured. Mental models enable an individual to describe, explain and make predictions about system operation. It is advantageous for operators as well as OCC staff to form accurate mental models of complex systems because this enables them to anticipate future system states, formulate plans and troubleshoot effectively. (Parasuraman and Mouloua, 1996). Accurate mental models are thus vital in situation awareness, and ultimately human/system performance.

Since the OCC team member's mental model may not be completely accurate, it is not a safe approach to design simply to match the person's model. Rather, the team member's perceptual skills should be leveraged against complexity in order to support the development of a more accurate and complete model. The goal of this approach is to encourage "exploration and discovery at the interface so that operators can accommodate the actual work constraints into their mental representations of the problem space." (Parasuraman and Mouloua, 1996). 
Comprehension is essentially a diagnostic task, and thus a conscious process. However, comprehension is influenced by existing mental models, that is, information is interpreted within an existing frame of reference. This effect may be mitigated by training, but unless special effort is made to change the existing mental model, operators will be inclined to fall back on familiar, unconscious patterns of behavior in stressful situations. Therefore, comprehension alone does not form a mental model; it will at best update it. To form a new mental model, focused training, appropriate visualizations, and even behavioral modification may be required. The process of comprehending, which can be regarded as part of semiosis, can be defined as an interpretative process through which the general and particular aspects of signs or events are systematically examined and the results are then related to what is already known by the interpreter. Like the process of semiosis itself, it involves a lot of recursion and self-referencing, moving from one level of meaning to another, until the interpreter is confident of a satisfactory interpretation.

If one accepts that situation awareness is affected by the amount of useable information in the task environment at any time, then one must also accept that the operator's mental model will be characterized by high semantic content, particularly derived from abstract or concrete visual information, procedural guidance and rules, and auditory and tactile information. In addition to the overt characteristics of the sense-making process, situation awareness is also affected by the interaction between the operator and the human system interface (HSI), as well as the communication process that serves to structure meaning in the operator's mental model. This implies that optimal situation awareness must is dependent on the effectiveness and communicability of signs in the workplace in general, and the human-system interfaces in particular.

We find that these concepts are embodied in well-known physical environments:

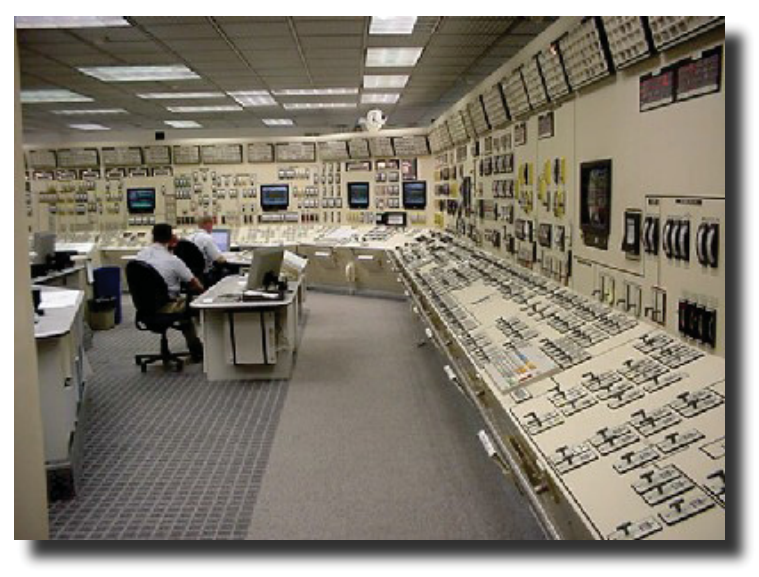

Analog control rooms are more concrete, less symbolic. Operators control the plant primarily at the component level, relying on single indicators, single values, and single controls for single functions.

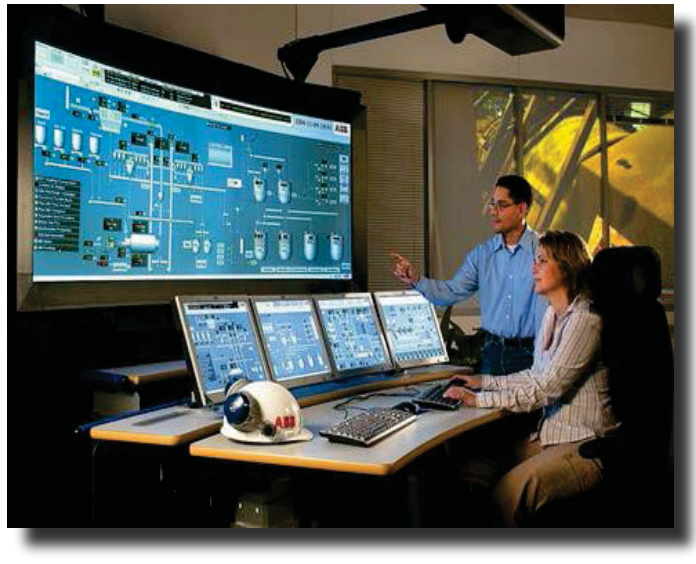

Digital control rooms are more symbolic, less concrete. Operators control the plant at the process level, using integrated indications, integrated values, and group controls for process sequences. 


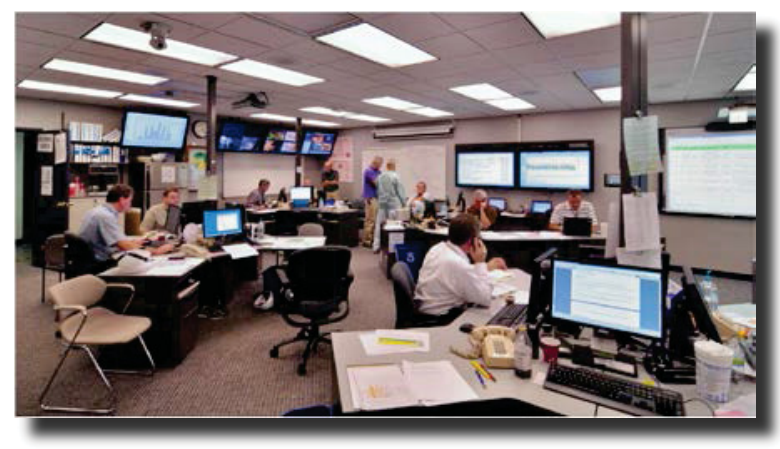

Conventional OCC: More concrete, less symbolic. Work relies on large amounts of textual and verbal communication, i.e. textual and verbal signifiers, but inadequate signification.

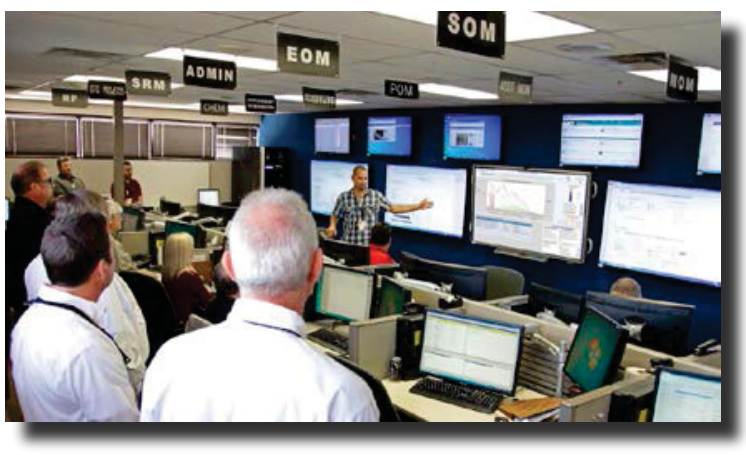

Improved OCC: More symbolic, less concrete. More graphical signifiers and improved signification, less reliance on textual communication.

\subsection{Semiotics}

\subsubsection{Semiotics in Linguistics}

The previous section dealt with the importance of meaning, comprehension, and making sense of signs. These are concepts that are integral to Semiotics, which is a field derived from linguistics and can simply be called "the study of signs and meaning". The field has formulated the notion of the semiotic sign that serves as the theoretical basis for any perceptive phenomenon, be it internal or external to the perceiver. When it is applied to visual communication, it deals with the visual nature of any representation of quantitative and qualitative information with a diversity and complexity of signs. According to one of the models in semiotic theory, a sign is defined in terms of the dyadic relationship between the signifier and the signified. The "signifier" is the form that the sign takes, something that can be perceived by the senses, for example, an icon in the operator interface that represents a pump. The "signified" is the concept to which it refers, which can be a mental construct (for example, "transfer of liquid"), or something concrete in the world, such as a physical pump, to which a particular object on a display refers. The same applies to any imaginable visual object on a display, whether graphical, numerical, or textual. The interaction between such objects (signifiers) and their meaning (signified) is a perceptive-cognitive process of converting the visual representations ("signs") into meaning within a given context (with the context itself being another sign). This sense-making process is known in semiotics as "semiosis", that is, the innate human ability to connect how we think with what we see, and vice versa - hence the expression "I see" as a substitute for "I understand." When we make sense of something, we refer to what we have learned as "insight." This is an everyday challenge for all humans who unconsciously and continually are confronted by the question: "how do I know that what I see means what I think it does?" This is the origin of many usability problems in software, that is, the disparity between how a designer represented the functionality of a system in the user interface, and the extent to which the user is able to use that interface with effectiveness, efficiency, satisfaction, and safety.

\subsubsection{Computer Semiotics}

Semiotics has been used extensively in the analysis of computer systems, and particularly concerning the user-interface (Barr et al., 2005). This included detailed work on the concept of "algebraic semiotics" (Goguen, 1999). The theory behind this approach is that computational semiotics can be formalized and thus become similar to mathematics in its application. For example, algebraic semiotics has been applied to the user-interface in considerable detail to show how semiotics can contribute to the understanding of computers as sign-systems (Andersen, 2006). Other approaches to computer semiotics have analyzed their use for graphic design, modeling user-interface elements, informing the design process, and analyzing 
whole environments as semiotic spaces that have a significant influence on human performance (Hugo, 2005).

It is clear from this brief survey that semiotics is an accepted approach to explaining computer systems as well as the organizational, conceptual, functional or physical environments within which they are found. Semiotics can be an approach that is suitable to more than just a superficial investigation of the role and meaning of signs in any of those contexts.

\subsubsection{OCC Semiotics}

For the purposes of this report, the notion of "Outage Control Center Semiotics" is defined as "a study of signs and meaning in Nuclear Power Plant Outage Information Management". This includes the generation, processing, and presentation of primarily quantitative, but also qualitative, information. The implication is that this approach would benefit from the integration of principles from human factors, semiotics and visual analytics, into a subset that focuses specifically on task performance through optimal information representation and communication.

Communication (and therefore interaction in the OCC with various communication media) is mediated by signs (e.g., icons, symbols, text, and speech), which in turn are representations of other signs. In terms of this concept, the OCC can be regarded as a semiotic space characterized by various forms of representation (iconic, indexical, or symbolic, ranging from abstract to concrete) and structured in four different sign forms: lexical (the "vocabulary" or collection of signs), semantic (the meaning of signs), syntactic (the syntax or rules for constructing the relations between signs) and pragmatic (the relation between signs and their interpreters).

For the sake of simplicity, the dyadic relation of a signifier (i.e., the form of the sign) to the signified (the concept to which it refers) can be described as either iconic (some kind of similarity - a sign that looks like the object it represents), indexical (a sign that abstractly represents some kind of causal relation), or symbolic (a sign that abstractly represents some kind of convention or rule).

A visual analytic approach to understanding the nature of the information would consider optimal ways of translating abstract, numerical information into graphical representations (i.e., making the abstract concrete). A semiotic approach would consider the reasons why some visual representations in the OCC are better than others. It is possible to map these translations between sign systems (for example, from plant to mimic diagram, system to icon, event to alarm sound). These maps are called semiotic morphisms (Goguen, 2000), and they can be qualitatively analyzed for consistency, coherence and complexity (Hugo, 2005).

\subsubsection{The OCC as Semiotic Space}

It is not the purpose of this report to delve too deeply into the arcane depths of semiotics. We will simplify the concept "semiotic space" as "a virtual space for sign processes". Some writers refer to a semiotic space as a "semiosphere", which represents a holistic approach that considers the totality of all sign users, texts, and codes of a culture, community, or workgroup (with the OCC as a typical example) which makes sign processes possible. (Goguen, 2000; Lotman, 1990). According to this approach, each semiosphere is unique in terms of its homogeneity, its contrast to the exterior, and the irregularities in its internal structure. The border between the interior and the exterior of a semiosphere is maintained by the unique characteristics of sign users, texts, and codes, all of which are subject to various processes of translation from sign to meaning. This is a reasonable description of most complex, dynamic environments like control rooms and OCCs. The irregularity in the internal functional structure of the OCC is responsible for the inner dynamics of that semiosphere. The semiosphere has a center (which can be called the "interactive sphere", consisting of the OCC staff and all sources of information and communication media) that is surrounded by functional areas (for example the various specialized OCC functions) which become increasingly amorphous in the direction of the periphery. The center (the interactive sphere) contains the dominating sign systems which include sign users, text, symbols, icons, 
indexes and codes that are elaborately tuned to each other. In the periphery, there are also sign users (supervisors, engineers, managers, planners, technicians, systems, etc.) who may not have a code in common and share only parts of a code which easily becomes incomprehensible the further their conceptual distance from the center. This is either because their codes have been lost through disuse or because the codes are heterogeneous and fragmentary due to diversity of training, knowledge, experience, standards, etc. Exchanges take place between interior and exterior (that is, between the OCC, the plant, and the rest of the organization) and between the interactive sphere and periphery (the areas and entities immediately outside the OCC, for example Plant General Manager's office, Outage Director's office, and other supporting facilities). These exchanges lead to the emergence of new codes, the production of new types of messages, and changes in the sign users which make them receptive to new meaning, which is essential to ensure overall operability of the OCC information media. This is exemplified in the volume, complexity and diversity of communication sources, channels, and media throughout the outage process.

\subsubsection{The OCC as semiotic morphism}

The information space of the OCC, like the main control room, is a combination of physical and virtual (electronic) constructs. It is governed and defined by a set of syntactic and semantic rules and it can thus be seen as an expression of a subset of known semiotic systems. In semiotic terms, the OCC is characterized by an abundance of concrete as well as abstract signifiers instantiated in artifacts like individual computer workstations and one or more large display panels for outage information. When we delve deeper into its structure, the OCC may be defined as a high order, complex sign consisting of a web of many other complex signs. In this semiotic space all signs are coordinated to work together to express a particular model of the world (that is, the outage and all aspects of the plant affected by the outage process). This means that the outage process and its related environments is a complex sociotechnical system characterized by complex patterns of communication flows and activities influenced by human, material, technology, and information entities, each of which has significance in a particular context. Because of the relationship between signifiers (words, signs and symbols) and their denotation in this sociotechnical system, quite literally, nothing is without meaning or without an intended message. In this way the semiotic space of the OCC is constructed from the synthesis of all syntactic and pragmatic elements. This construct can be regarded as a semiotic morphism which in the following discussion will be referred to as the paradigmatic-syntagmatic framework (PSF). This is explicated in more detail below and illustrated in Table 1, Figure 1, and Table 2.

\subsubsection{A formal model for dashboard design}

Because of its usefulness in explicating the relationship between signs and meaning, a semiotic approach to the design of AOCC information supports the cognitive-semantic aspects of sign composition and is thus well suited to the analysis and design of displays in this complex task domain. However, it could easily be argued that this involvement in rather abstract decompositions of what would otherwise be regarded as "intuitive design" may trap the analyst in detail that obscures the "big picture". To overcome this difficulty, a coherent taxonomy or framework of structured representations would provide a practical way to ensure consistency and coherence in the display architecture of the visual design (Hugo, 1992, 2005). Since such a coherent framework will also help to structure the semantic architecture of dashboards and HSIs, it should be possible to ascertain with a greater degree of accuracy and confidence why, how and when certain display and instrument configurations promote and others inhibit comprehension, situation awareness, and general human performance. In terms of theories and models of visual communication, the relationship between the presentation of visual artifacts, their perception by humans, and the interpretation of the meaning of the visual signs, can form the basis of a formal set of principles and patterns that can guide the rational design of information dashboards. Thus, an analysis of the semantic and syntactic architecture of the display within the PSF would also help to assess the "semiotic adequacy" of the display, in other words, why a particular instantiation of a display is better to promote performance than another. 
In all modes of communication, meaning arises from the differences between signifiers, that is, "signs", or the perceptible elements of a communication that are intended to convey meaning and ultimately to trigger some kind of mental or physical response from the recipient. In semiotic engineering (de Souza, 2005), these differences are described as either paradigmatic or syntagmatic. All signs, whether visual, verbal, numerical or textual, have these paradigmatic-syntagmatic dimensions and they treat signs as part of a system that determines the "value" of a sign.

The paradigmatic dimension identifies the sign as an element in a set of signs that have a common function. A semiotic paradigm serves as a contrastive factor because signifiers ("signs") in a paradigm set will shape each other's preferred meaning by virtue of mental associations. For example, a set of icons, symbols, words or numbers.

The syntagmatic dimension refers to the combination of signifiers from a specific semiotic paradigm to form a meaningful order, or syntax. Such syntagms are commonly found in the structure of visual communication, such as drawing, painting, television, cinema, and graphical user interfaces. In this context, a syntagm can be defined as an orderly combination of interacting signifiers that form a meaningful whole in a display, which means it is a combination of selected elements from all possible paradigms.

The syntagmatic analysis of the semiotic space (whether the information within it is verbal or nonverbal) involves studying its structure and the relationships between its parts. This analysis seeks to identify elementary constituent segments within the domain - its syntagms. The syntagmatic relations reveal the conventions or 'rules of combination' underlying the production and interpretation of meaning (such as in the grammar of a language). The use of one syntagmatic structure rather than another within the domain, or within a particular message, influences meaning. Some syntagmatic forms may be based on spatial relationships (for example, the arrangement of graphical or textual objects on a human-system interface, which works through juxtaposition) and on conceptual relationships (such as the appearance of such objects in a particular operational, technical or functional context) (Chandler, 2007). The OCC contains, by definition, multiple syntagmatic structures, as shown in Figure 1.

Syntagms in HSIs are identified in five groups or relationships that describe the signifiers in the HSI from various perspectives and levels of detail (see Table 1):

1. Physical Interaction System (PS)

2. Subject Matter (SM)

3. Spatial Organization (SO)

4. Figurative Screen Image (FI)

5. Discrete Signs (DS)

Together syntagms and paradigms create a framework that provides a coherent, structural context within which signs make sense. A simple and convenient notation to express these relationships can be adapted from Set Theory, where a set is simply expressed as $\{1,2,3,4 \ldots\}$. Where different instantiations of a user interface are compared, the appearance of the same signifiers in both instances would be expressed as a Union: $\mathrm{C} \cup \mathrm{D}=\{1,2,3,4,5\}$. Set notation could also be used to describe instances of intersection, in other words, where some signifiers appear as a Subset in both instances: $\{3,4,5\} \subseteq \mathrm{D}$.

A semiotic paradigm in an HSI is the selection of alternative elements to create functional contrasts between signifiers (for example, "analog instrument or digital instrument or trend graph", etc.). Simple set notation could be applied to, for example, a paradigm of Spatial Organization for "System Information" that identifies the following syntagms:

A: 2-Dimensional field (text, numerical values, static line graph)

B: 3-Dimensional field (photo, 3D image)

C: Temporal Dimension (video footage, dynamic trend graph) 
For a mutually exclusive instance, this paradigm could be expressed as $\mathbf{S O}\{\mathbf{A}, \mathbf{B}, \mathbf{C}\}$, which reads: "the spatial presentation of system information will employ 2-dimensional spatial layouts or 3-dimensional component images or dynamic trends graphs and video".

Similarly, a syntagm for an individual display $(\mathrm{X})$ would be expressed as:

\section{Interface Instance $(X)=\{$ PS,SM,SO,FI,DS $\}$}

This is exemplified in the following syntagmatic sentence (words in italics are added to render a grammatically readable statement):

$\mathrm{SO}\{\mathrm{A}\}$ "The LCD monitor (displays)" + $\mathrm{SM}\{\mathrm{A}, \mathrm{B}\}$ "controls (for the) main cooling cycle" + $\mathrm{SO}\{\mathrm{A}\}$ "(as a) flowchart" + FI $\{\mathrm{A}\}$ "at $1280 \times 1024$ resolution" + DS $\{\mathrm{A}, \mathrm{B}\}$ "(using) abstract and concrete representations (of) plant equipment".

The following tables explain the implementation of these concepts in the PSF approach. The first table shows the basic framework without content:

Table 1: The Paradigmatic/Syntagmatic Framework

\begin{tabular}{|c|c|c|c|c|c|}
\hline & \multicolumn{2}{|c|}{ MACRO LEVEL } & \multicolumn{2}{|c|}{ MESO LEVEL } & \multirow{2}{*}{$\begin{array}{l}\text { MICRO LEVEL } \\
\begin{array}{c}\text { Discrete Signs } \\
\text { (DS) }\end{array}\end{array}$} \\
\hline Horizontal Syntagms & \begin{tabular}{|c|} 
Physical Interaction \\
System \\
(PS) \\
\end{tabular} & $\begin{array}{l}\text { Subject Matter } \\
\text { (SM) }\end{array}$ & $\begin{array}{c}\text { Spatial } \\
\text { Organisation } \\
\text { (SO) } \\
\end{array}$ & $\begin{array}{c}\begin{array}{c}\text { Figurative screen } \\
\text { image } \\
\text { (FI) }\end{array} \\
\end{array}$ & \\
\hline \multirow{4}{*}{ 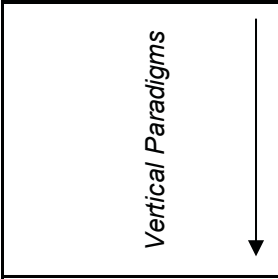 } & $\begin{array}{l}\begin{array}{l}\text { A. Computer } \\
\text { Hardware }\end{array} \\
\end{array}$ & A. Category / domain & $\begin{array}{l}\text { A. 2-Dimensional } \\
\text { field }\end{array}$ & $\begin{array}{l}\text { A. Size, brightness, } \\
\text { resolution }\end{array}$ & A. Shapes \& forms \\
\hline & B. Software & B. Complexity Level & $\begin{array}{l}\text { B. 3-Dimensional } \\
\text { field }\end{array}$ & B. Color & B. Icons \\
\hline & C. Environment & $\begin{array}{l}\text { C. Graphic / } \\
\text { symbolic / textual }\end{array}$ & \begin{tabular}{|l|} 
C. Temporal \\
dimension
\end{tabular} & $\begin{array}{l}\text { C. Level of } \\
\text { realism/abstraction }\end{array}$ & C. Indexes \\
\hline & & $\begin{array}{l}\text { D. Concrete / } \\
\text { abstract }\end{array}$ & & $\begin{array}{l}\text { D. Composition, } \\
\text { layout, image }\end{array}$ & D. Symbols \\
\hline Signifier level & \multicolumn{5}{|c|}{ Size of Objects/Signs, Spatiality, Contrast, Shape, Form, Colour, Texture } \\
\hline Signification level & \multicolumn{5}{|c|}{$\begin{array}{c}\text { Connotative \& Denotative content: } \\
\text { Arbitrary Signs - figurative represtentations, realistic images } \\
\text { Logical, cognitive or denotative content } \\
\text { Connotative or associative meaning } \\
\text { Stylistic meaning } \\
\text { Affective meaning }\end{array}$} \\
\hline Syntagms & $P S\{A, B, C \ldots\}$ & $\operatorname{SM}\{A, B, C \ldots\}$ & $\mathrm{SO}\{\mathrm{A}, \mathrm{B}, \mathrm{C} \ldots\}$ & $\mathrm{FI}\{\mathrm{A}, \mathrm{B}, \mathrm{C} \ldots\}$ & $\mathrm{DS}\{\mathrm{A}, \mathrm{B}, \mathrm{C} \ldots\}$ \\
\hline $\begin{array}{l}\text { Syntagmatic Individual } \\
\text { Interface }(X) \text { thus } \\
\text { expressed by: }\end{array}$ & \multicolumn{5}{|c|}{$X=\{P S, S M, S O, F I, D S\}$} \\
\hline
\end{tabular}

This framework can be simplified in the following hierarchical model: 


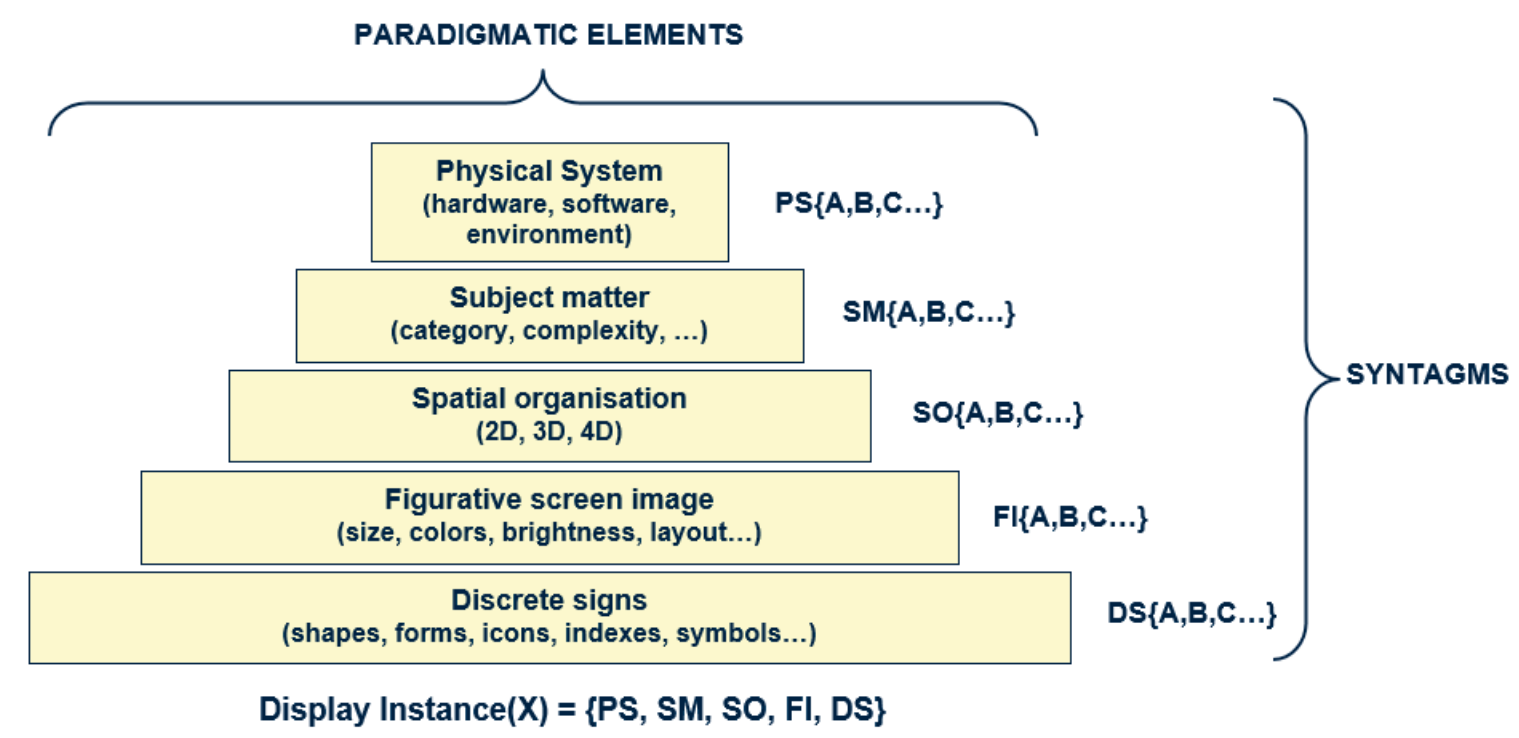

Figure 1: Hierarchical Model of the PS Framework

This framework can also be regarded as an ontology of the semiotic space where horizontal paradigms are linked epistemically to the lower ontological levels.

As an example, the following table illustrates the application of this framework to a very specific domain: advanced digital alarm generation, processing and presentation in the control room: 
Table 2: Paradigmatic-Syntagmatic Framework - Example for Alarms and Annunciators

\begin{tabular}{|c|c|c|c|c|c|}
\hline \multirow[b]{2}{*}{$\begin{array}{l}\text { Horizontal } \\
\text { Syntagms }\end{array}$} & \multicolumn{2}{|c|}{ MACRO LEVEL } & \multicolumn{2}{|c|}{ MESO LEVEL } & \multirow{2}{*}{$\begin{array}{c}\text { MICRO LEVEL } \\
\text { Discrete Signs } \\
\text { (DS) }\end{array}$} \\
\hline & $\begin{array}{c}\text { Physical Interaction } \\
\text { System } \\
\text { (PS) }\end{array}$ & $\begin{array}{l}\text { Subject Matter } \\
\text { (SM) }\end{array}$ & $\begin{array}{c}\text { Spatial organization } \\
\text { (SO) }\end{array}$ & $\begin{array}{l}\text { Figurative screen } \\
\text { image } \\
\text { (FI) }\end{array}$ & \\
\hline \multirow[t]{2}{*}{ 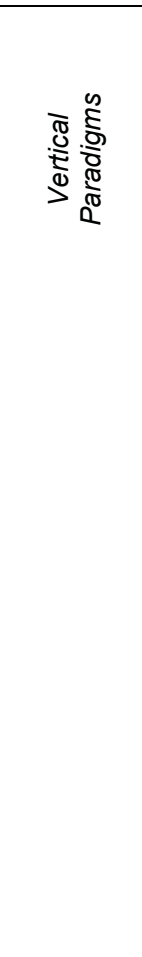 } & $\begin{array}{l}\text { A. Computer Hardware: } \\
\text { LCD monitor, wide panel } \\
\text { displays, keyboards, } \\
\text { mouse, printers, buttons } \\
\text { (shutdown controls, etc.) }\end{array}$ & $\begin{array}{l}\text { A. Category: Nuclear Power } \\
\text { Station Control }\end{array}$ & $\begin{array}{l}\text { A. 2-Dimensional field: } \\
\text { Structural representation of } \\
\text { plant and equipment }\end{array}$ & $\begin{array}{l}\text { A. Size, brightness, resolution: } \\
\text { operator displays are: } 23 \text { inch } \\
\text { LCD panels at } 1280 \times 1024 \\
\text { pixels. Wide display panels } \\
\text { (SDCV) are } 150 \mathrm{~cm} \text { plasma } \\
\text { displays at } 1024 \times 768 \text { pixels. } \\
\text { Brightness is adjustable by } \\
\text { operator. }\end{array}$ & $\begin{array}{l}\text { A. Shapes \& forms: } \\
\text { - Mode/State \& performance } \\
\text { diagrams } \\
\text { - Process diagrams \& } \\
\text { flowcharts } \\
\text { - Alarm and event lists } \\
\text { - Display shortcuts (icons) } \\
\text { - Faceplates (control panels) } \\
\text { - Text (alarm lists) \& messages } \\
\text { - Graphs, } \\
\text { - Toolbars, scroll bars, status } \\
\text { bars, buttons, etc. }\end{array}$ \\
\hline & $\begin{array}{l}\text { B. Software: Operating } \\
\text { system, User Interface } \\
\text { Management System, } \\
\text { Automation System, I\&C } \\
\text { system }\end{array}$ & $\begin{array}{l}\text { B. Level of complexity: Very } \\
\text { high }\end{array}$ & $\begin{array}{l}\text { B. 3-Dimensional field: } \\
\text { Physical appearance and } \\
\text { spatial relationships of } \\
\text { equipment }\end{array}$ & $\begin{array}{l}\text { B. Color: used to convey } \\
\text { specific information and to } \\
\text { categorize graphic elements. } \\
\text { Within the limitation of } \\
\text { maximum } 4 \text { colors per display, } \\
\text { standardized color is also used } \\
\text { to indicate interface } \\
\text { backgrounds, functional areas } \\
\text { and objects. }\end{array}$ & $\begin{array}{l}\text { B. Icons: Function shortcuts, } \\
\text { display shortcuts }\end{array}$ \\
\hline
\end{tabular}




\begin{tabular}{|c|c|c|c|c|c|}
\hline & $\begin{array}{l}\text { C. Environment: control } \\
\text { room structure, consoles, } \\
\text { desks, communication } \\
\text { equipment, storage, } \\
\text { seating, lighting, etc. }\end{array}$ & $\begin{array}{l}\text { C. Combination of graphic, } \\
\text { symbolic, textual }\end{array}$ & $\begin{array}{l}\text { C. 4-Dimensional Field } \\
\text { (Temporal dimension): } \\
\text { Change of graph lines over } \\
\text { time, valve position change, } \\
\text { simulated flow in pipes, } \\
\text { animation of machine parts, } \\
\text { etc. }\end{array}$ & $\begin{array}{l}\text { C. Level of realism/abstraction: } \\
\text { Top levels of the HSI employ } \\
\text { abstract metaphors (e.g. } \\
\text { mode/state diagrams) and } \\
\text { lower levels employ more } \\
\text { concrete metaphors with } \\
\text { realistic or stylized objects to } \\
\text { represent plant and equipment. }\end{array}$ & $\begin{array}{l}\text { C. Symbols: electrical, } \\
\text { mechanical, hydraulic and } \\
\text { pneumatic equipment symbols } \\
\text { - motors, pumps, valves, circuit } \\
\text { breakers, vessels, cooling } \\
\text { towers, reactors, tanks, bins, } \\
\text { pipes, transformers, resistors, } \\
\text { gearboxes, filters, heat } \\
\text { exchangers, compressors, } \\
\text { blowers, turbines, etc. }\end{array}$ \\
\hline & & $\begin{array}{l}\text { D. Concrete: physical } \\
\text { layout \& characteristics of } \\
\text { equipment (reactor vessel, } \\
\text { S/G, turbines, pipes, } \\
\text { pumps, etc.) } \\
\text { Abstract: system modes \& } \\
\text { states, process flow, } \\
\text { system performance }\end{array}$ & & $\begin{array}{l}\text { D. Composition, layout, image } \\
\text { complexity: Composition and } \\
\text { layout follow the operator's } \\
\text { natural task flow. Images are } \\
\text { kept as simple as possible to } \\
\text { avoid ambiguity and visual } \\
\text { noise. }\end{array}$ & $\begin{array}{l}\text { D. Indexes: alarm lights and } \\
\text { sounds, trend graphs, gauge } \\
\text { pointers, values }\end{array}$ \\
\hline Signifier level & \multicolumn{5}{|c|}{$\begin{array}{l}\text { Spatiality: alarm objects and signs are not arranged on the display to correspond to the spatial layout of the plant, but to reflect the logical flow of the process. } \\
\text { Contrast: active (alarmed) objects are highlighted to achieve the highest possible contrast with the display background. Inactive objects are displayed with lower } \\
\text { contrast so that operator can focus on active objects. } \\
\text { Shape: Objects are either represented as stylized, recognizable forms (vessels, turbines, motors, etc.) or as abstract symbols (circuit breakers, valves, etc.) } \\
\text { Color: Equipment and indications are color coded. Colors used on any display generally limited to 4. Backgrounds are consistently dark grey. } \\
\text { Texture: This is generally avoided in the HSI since it introduces too much visual noise. } \\
\text { Metaphor: Ideally plant physical and abstract flows in combination with ecological relationships (e.g. thermodynamic behavior of critical systems) and other } \\
\text { attributes are used as metaphor. This is ideally implemented as state or flow diagrams. Abstract metaphors based on the thermo-hydraulic characteristics of the } \\
\text { process are also used and represented as abstract, dynamic diagrams (e.g. efficiency diagrams plotting entropy against temperature, and other types of } \\
\text { ecological interfaces). }\end{array}$} \\
\hline Signification level & \multicolumn{5}{|c|}{$\begin{array}{l}\text { Connotative \& Denotative content: } \\
\text { Arbitrary Signs: } \\
\text { - abstract symbols for alarm status, processes and objects } \\
\text { - trend graphs to indicate temperature, pressure, flow, set points, limits, etc. } \\
\text { - text, diagrams, graphs to represent plant or system performance and status } \\
\text { - digital instruments (numeric values \& labels) } \\
\text { Figurative representations (object schemata): } \\
\text { - realistic or semi-realistic images - Reactor vessel, steam generators, pressurizer, turbines, generator, pumps, valves, etc. to represent corresponding } \\
\text { equipment } \\
\text { - analogue instruments (where appropriate) - dial faces, pointers, frames, etc. to represent process parameter (pressure, temperature, reactivity, etc.) }\end{array}$} \\
\hline
\end{tabular}


Logical, cognitive or denotative content:

Images on screen are recognized as abstract process flow diagrams and status indicators, and as concrete vessels, turbines, pipes, graphs, etc.

Connotative or associative meaning:

Example: a specific value on a specific temperature gauge in a specific flow diagram on a specific process display is associated with bearing temperature on the power turbine generator, the outline and form of a symbol indicates a specific type of valve, etc.

Stylistic meaning (layout, context, etc.):

For example, the spatial relationship between representations of valves on a process display indicates direction of flow, lines between symbols indicate dependency or isolation, relative size of symbols indicate importance of physical size, presence of a "flag" near a component symbol indicates component status (e.g. running, stopped, alarmed, maintenance), spatial relationship, location and pattern of active alarm tiles on the SDCV indicate a specific system fault or emergency, etc.

\begin{tabular}{|c|c|}
\hline \multirow[t]{5}{*}{ Syntagms: } & $\begin{array}{l}\text { 1. Physical Interaction System is expressed by the paradigms of computer hardware, software and physical environment within which the operator performs } \\
\text { his tasks. }\end{array}$ \\
\hline & $\begin{array}{l}\text { 2. Subject Matter is expressed by the paradigm of nuclear power station control with a high complexity, employing a combination of textual, graphical and } \\
\text { symbolic information representation, ranging from concrete to abstract. }\end{array}$ \\
\hline & $\begin{array}{l}\text { 3. Spatial organization is expressed by the paradigm of the 2-dimensional layout of the operator interface screens (emphasis on SDCV and alarm lists), the } \\
\text { representation of concrete objects and the indication of dynamic changes of time during the execution of a process. }\end{array}$ \\
\hline & $\begin{array}{l}\text { 4. The figurative screen image is constructed from the paradigms of size, brightness, resolution, color, level of realism or abstraction, and composition and } \\
\text { layout of alarm objects. }\end{array}$ \\
\hline & 5. Discrete signs in the interface are constructed from the paradigms of shape and form, icons, symbols and indexes used to distinguish alarms. \\
\hline $\begin{array}{l}\text { Individual } \\
\text { syntagm: }\end{array}$ & $\begin{array}{l}\text { Meaning is thus represented at three levels: } \\
\text { - The "frame message" by the vertical paradigms that form the } 5 \text { syntagms. } \\
\text { - } \quad \text { Denotative meaning at the figurative level is represented by the signifiers of spatiality, contrast, shape, color, texture and metaphor. } \\
\text { - Connotative meaning at the interpretive level is represented by the signification functions of context and association. }\end{array}$ \\
\hline
\end{tabular}


With reference to the earlier discussion of Meaning, we can now see that a paradigmatic connotation results when the meaning of a specific interface is derived from the knowledge that it is a choice from among other representations, e.g. the same system or process. Syntagmatic connotation results when meaning is not derived from a single element on the interface from among others, but based upon a comparison with other signs on the same display, or with preceding and succeeding displays. The difference between actual (current) and "potential" displays determines the connotation. Since this has a direct bearing on OCCs staff's ability to predict the future state of the system, it also has a direct influence on situation awareness.

As shown in Table 2, at the signification level of the PSF, connotative meaning is influenced by a large number of factors, including what is often referred to as "conventions." In fact, some conventions have become so pervasive that they acquire denotative meaning, for example the "conventional meaning" of objects in the Microsoft Windows ${ }^{\circledR}$ user interface. As Dekker and Hollnagel (2004) point out, such conventions result from assumptions about "...non-observable constructs that are conveniently endowed with the necessary causal power without any specification of the mechanism responsible for such causation”. (p. 80). Although they were referring more to the consequences of inferences made about the reason for operator behavior and performance deficiencies, this has a direct bearing on the influence that erroneous assumptions about the meaning of representation in the HSI or dashboard may have on staff's mental models. The PSF approach would largely avoid this problem because the focus is firstly on the objective characteristics of discrete elements, and secondly on understanding the nature of the process of semiosis in the OCC. It is vital that the signification level of the dashboard, and especially the origin of connotative meaning, be included in the understanding of situation awareness. The obvious reason is because connotative meaning based on false conventions may result in inaccurate mental models.

Similarly, one should guard against interpretations of outage information that make assumptions about patterns of reasoning, because these may be based upon convention. Instead of descriptions of cognitive aspects of work based on working memory management, mental workload, situation awareness, mental models, meta-cognitive self-monitoring and patterns of reasoning, one should rather ignore "internal states" and focus on actual observable performance. This may be a more practical approach, but neither approach takes account of semiosis and the process of comprehension, and its influence on the individual worker's mental model, which ultimately affects behavior and performance.

\section{Presentation of Information in the OCC}

Past experience in many OCCs provide compelling evidence that existing ways of providing outage performance information is suboptimal. With the advent of sophisticated software, large, high-resolution

display panels, and versatile hand-held devices, it is now possible to eliminate paper and create a HSI on a range of devices that are easy to use and will likely lead to significant improvements in communication, as well as maintenance and work management processes.

This project has provided evidence that semiotics and visual analytics together are particularly relevant in work domains characterized by electronic communication media, because they are so rich in different forms of visual representation. Both fields are also closely associated with human-system interaction and situation awareness, two of the cornerstones of human performance in nuclear power plants. The combination of these methods creates a powerful, direct interface between human, data, system and environment, thus amplifying human cognitive capabilities in six basic ways:

1. Visual communication in general, and the semiotic approach in particular, improves our understanding of how the appearance of specific objects in the real world influences the communication process, and specifically the way such objects are interpreted and how they contribute to the development of mental models of environments, functions and operations;

2. Translating complex, abstract data into directly accessible visual information increases human cognitive resources by providing an external visual resource to expand human working memory. 
This helps to simplify and reduce the need to search for information by representing a large amount of integrated and synthesized data in a small space;

3. By understanding the relationship between a sign, its meaning in the overall outage context, we will have a clearer understanding of the reasons why different representational modalities are better than others to convey operational information in specific contexts, thereby improving the chances of achieving the required performance;

4. It enhances the observer's ability to recognize patterns, for example by organizing information spatially, by time relationships, by function, etc. This also supports easy perceptual inference of relationships that are otherwise more difficult to deduce;

5. It supports situation awareness by simplifying the monitoring of a large number of potential events;

6. Finally, visual analytics helps to create a coherent, consistent, interactive, manipulable medium that, unlike static, raw data diagrams, enables the exploration of the AOCC information space.

Ultimately, visual representations of information help us work around a fundamental limitation that is built into our brains - a limited capacity to store information for immediate recall. Although we have tremendous long-term memory capacity, working memory (also known as short-term memory) is extremely limited. Graphical representations of quantitative information allow people to store the entire pattern formed by the shape of the graph (histogram, trend graph, pie chart, etc.) as a single chunk of memory. This means that we can store much more information within the limitations of short termmemory than we could if the values were written as numbers. Simply by encoding information visually, our ability to think about it can be significantly expanded by making more of it available at any one moment.

\subsection{Outage Information and Situation Awareness}

Most of the activities during an outage require constant monitoring in real-time or near-time, because delays in responding cannot be tolerated without impacting schedules and cost. This is why outage information must be designed to support real-time collective situation awareness, in the same way that operators in the control room need to be constantly aware of the plant's condition to ensure safe and effective operations. Information displayed in the OCC must grab the attention of the OCC staff when it is needed, it must make it easy to spot what is most important in a screen full of data, and it must give all team members the means to understand the status and importance of all conditions and activities and respond without little or no delay. To do this, they require expert visual design to ensure that the displays express measures of performance clearly, accurately, directly, and without distraction.

The need for optimal situation awareness was mentioned in the FY14 AOCC milestone report (St Germain et al., 2014) but without mentioning the design, type and quality of information represented in the OCC. Endsley et al. (2003) define situation awareness as follows:

"Situation awareness is being aware of what is happening around you and understanding

what that information means to you now and in the future. This awareness is usually defined in terms of what information is important for a particular job or goal. The concept of situation awareness is usually applied to operational situations, where people must have situation awareness for a specified reason, for example in order to drive a car, treat a patient, or separate traffic as an air traffic controller." 
Situation awareness involves three levels of awareness that apply in any work domain: 1) the perception of one's environment, 2) comprehension of its meaning, and 3) the ability to project that understanding into the future to anticipate what might happen.

This definition is actually a very accurate description of the requirements for optimal outage performance and it implies that all critical performance measures should be designed to support the execution of individual, as well as collective outage activities. In addition, this means that an information display that is designed to support situation awareness must support all three levels of awareness. Failure in any of these areas will undermine the effectiveness of the information displays and thus reduce overall outage performance. However, the entire weight of responsibility for the success or failure of the information displays does not fall on the display alone. Workers who use the information must thoroughly understand the domain. They have already constructed a mental model of the domain into which the information derived from the display can be rapidly integrated. However, a perfectly designed display will not overcome their lack of expertise and expertise cannot overcome the failures of the display to present information in a way that matches their individual or collective mental model.

Because of the unique cognitive and perceptual requirements posed by the complex information generated during outages, the effective design of an integrated information display requires an understanding of human factors in general, and visual communication in particular - what works, what doesn't, and why. This involves an analysis of the nature, role, and composition of the discrete components of the visual elements in the displays. This is a necessary element in the analysis of situation awareness, due to the very nature of the processes of representation, communication and interpretation of information in all work domains. In fact, the semantic content of information artifacts in the OCC is so high that it should be treated as a complex, hierarchical architecture of meanings, expectations, targets, values, and measures.

As indicated above, optimum situation awareness requires knowledge of, for example, current outage performance parameters and the normal value of those parameters, the difference between current values and normal values, the past state of the process, and the predicted future state of the process. Situation awareness is maximized by integration of this information, and is thus critical when the OCC team members are confronted by a complex and changing situation. It is directly related to individual worker and joint team performance, and is especially important during abnormal conditions (e.g., emergent conditions such as equipment damage, leaks, releases, etc.) when personnel are required to identify situations and problems not covered by normal procedures, make correct diagnoses of faults, and decide on a path forward. Research has shown that the way in which information about the dynamic environment is represented in a person's mental model, plays a significant role in anticipation of certain events, and thus also affects a conscious attention and search for information. There is also common agreement that the work situation in complex industrial environments is characterized by high information content, which, if not managed properly, may contribute to excessive mental workload, and hence operator error.

It must be emphasized that more information is not necessarily better for optimal performance, because too much information can cause "cognitive clutter" and may interfere with effective response and appropriate mitigation. Methods of providing raw data to OCC team members are currently simplistic and do not exploit the potential of effective visual communication. Additionally, there is much more data available that is not typically evaluated, because methods have not yet been developed to process and integrate this information into something meaningful. We know that the schemata that make up a person's mental model are constructed through perception, attention, pattern matching, analysis, synthesis, and metacognitive processes. These are all directly associated with the process of semiosis (the process of engaging the senses in the interpretation of signs as referring to their objects, in an attempt to obtain meaning from visual representations), but situation awareness analysis techniques have so far not included this perspective. 
To understand how presentation of information in the OCC affects human performance and thus overall outage performance, we need to understand how information perceived by the worker acquires meaning in specific situations. More specifically, we need to ask how individual signs in OCC displays are distinguished from, and also related to, the total context, that is, how does the individual worker and also the team decide where to focus their attention, whether regarding the external world (the plant) or regarding their own interior world (mental model)? We also need to know what contributes to the perceptual salience of the information. How does the sign modify the worker's internal mental organization, that is, the mode of interpretation of the sign? These questions fall squarely in the domain of semiotics (that is, the study of signs and meaning). Measures of optimal situation awareness therefore need to include an analysis of the actual information that the OCC members deal with: location, type, duration (transience), frequency (repetition), structure, format, accuracy, origin, etc. (Hugo, 2005).

The foregoing discussion suggested that a combination of three disciplines, visual analytics, data analytics, and human factors, could provide the key to providing a set of tools to optimize situation awareness as well as operational and human performance. The result of such a combination is described in the following discussion.

\subsection{The Need for an Integrated Information Display}

As we have seen from observations during outages so far, to achieve even a single objective often requires access to a collection of information that is not necessarily related, often coming from diverse sources related to various outage, maintenance, and operational functions. This information is often difficult to classify due to large variability, and each recipient must spend some cognitive effort on determining the relevance to his or her job. This information can be one or more KPIs, it could be quantitative data, or it could be qualitative information that must be "translated" into information relevant to the task at hand.

A previous report (St. Germain et al., 2015) discussed the characteristics of a "good display" and how such a display and the data it represents would be intimately associated with the task of the user and the work domain within which it is used. The report pointed out that the method used to display data plays a key role in its usability. This means the extent to which a specific user can perform a specific task in a given context with effectiveness, efficiency, and satisfaction. The specific context, as described in this report, is multi-tiered, composed of the physical environment (the $\mathrm{OCC}$ ), and the various operational phases of the outage, as well as specific events during the outage. The specific user is any OCC crew member that needs up-to-date information on outage status. The specific task is making critical decisions regarding the outage schedule and application of resources.

Experience in many non-nuclear industries provides convincing evidence that so-called information dashboards are one of the most effective ways to improve situation awareness and therefore the ability to make well-informed decisions. When properly designed, a dashboard can reduce the complexity of massive amounts of disparate pieces of information from various sources and integrate all information on a single display panel. The outage information on a dashboard is presented as a combination of text and graphics, but with an emphasis on graphical representation. As explained above, dashboards are highly graphical, not to create "pretty pictures", but because graphical presentation, handled expertly, can often communicate with greater efficiency and richer meaning than text alone. The real power of an information dashboard lies in its ability to exploit the process of semiosis, described above. The design process must determine optimal ways to present the information so that it can be perceived quickly and intuitively and enable OCC team members to easily extract the correct and most important meanings from it.

The purpose of an outage information dashboard therefore is the visual display of the most important information needed to achieve one or more objectives of the outage, specifically critical decisions that would affect cost, time and resources. The amount of information required should be big enough to allow well-informed decisions, and small enough to avoid overwhelming the cognitive capacity of the 
performer. Ideally, all information required for critical, real-time decision-making should be observable at a glance and in a single, fixed location. This implies the need for an integrated collection of information that fits entirely on a single display panel so it can be monitored at a glance by all OCC team members. Some or all of the information could also be made available for dissemination to remote locations and handheld devices.

In addition to the visual characteristics of an integrated information displays, one of the most important requirements for an outage dashboard is that the information must be actionable. This means "nice to know" information does not belong on a dashboard; it wastes space, time, effort and resources. The key traits of meaningful, actionable data have been summarized by Few (2009):

- High volume (information-rich displays support decision-making)

- Historical (it is important to know how information changed over time)

- Consistent (format and definition of variables should not change over time)

- Multivariate (the more variables available, the better the ability to make informed decisions)

- Atomic (the ability to drill down to low levels of detail)

- Clean (information must be accurate and reliable)

- Clear (the meaning of data elements must be immediately recognizable)

- Dimensionally structured (a clear distinction between quantitative and qualitative data, facts and concepts)

- Richly segmented (segmentation of data into meaningful groups)

- Of known pedigree (the origin of data must be known and trustworthy)

The application of these principles in a well-designed dashboard, that is, one that applies human factors principles, data analytics, visual analytics, and semiotic techniques, produces some of its most noteworthy advantages:

- Reduce information complexity

- Reduce the number of alert conditions and instead improve the differentiation of alerts

- Aggregate and integrate disparate information

- Include analysis of past performance

- Ensure visual salience (the ability to focus on the right things for the right reason at the right time)

- Ensure a match between information and its visual representation (the right kind of graphic for the right kind of data)

- Direct expression of quantitative measures of performance

- Ensure coherence and understanding of overall context of activities

In addition to the advantages of efficient communication, a well-designed dashboard should also help the whole team to manage the bow wave of work. While the obvious approach is to avoid bow wave work and not to continually have to recover from its effects, information should be synthesized in a way that will enable operations staff to be ready with clearances and resources to support testing activities, and to release work based on priority and schedule (e.g., long duration work released first). This cannot be a one-sided approach and all disciplines should be consulted on how to improve production and barriers that can be removed - work has to be "READY-READY". This includes factoring emergent work into initial schedule loading, down to the crew level based on experience from previous outages. 
The introduction of an advanced outage dashboard in the OCC must be done in such a way that the various functions that OCC team members must perform will be retained, but the methods to accomplish these functions may change dramatically by using technology and reallocation of functions currently assigned to individuals. This might lead to a reduction in the number of staff that need to be physically located in the OCC. Previous assessments (see report INL/EXT-15-36489) have already indicated that introduction of hardware and software technology for communication and collaboration can improve the effective execution of an outage.

Reiterating the benefits of visual analytics described before, we can see that by placing all of the information needed to support decision-making during outages on a single display, it becomes possible to (1) reduce the need to rely on short-term memory, (2) reduce the need to supplement short-term memory by printing paper copies, (3) reduce the need to obtain information from other sources, (4) let the dashboard serve as an external form of memory, and (5) reduce the need to move the information into long term memory and instead enable moving it in and out of short term memory at lightning speed as you make sense of it.

\subsection{Dashboard Functional and Physical Characteristics}

Not all of the information available in the OCC will be equally important or necessary for the dashboard, which means all potential information items must be ranked and rationalized before embarking on the design of the dashboard. The following principles, some of which are also found in St. Germain et al. (2015), will guide the ranking:

- Which items are needed for immediate decision-making?

- Is there a need to see discrete data all the time?

- Is the discrete information alone valuable to the performer to accurately make the correct decision?

- Can the discrete data be displayed using color coding to provide additional information about the state or status of the process or system?

- Which items can be omitted because they do not support decision-making?

- What critical decisions are required by the performer?

- Which items will encourage active thinking about the data, not just passive reaction to alerts?

- Which items will provide team members a simple means to respond?

- Which collection of items will provide a common picture for the whole team?

- Which items will support projections for proactive responses (situation awareness)?

- Do the selected items jointly and individually match the team members' mental model?

- Can the data be displayed using a trending graphical display? Is this more a useful form?

- Will a digital or analog display or combination of the two improve understanding by the performer?

In addition to the functional requirements, consideration must also be given to the physical configuration of the displays, within the context of the physical OCC and also physical environments and workspaces outside the OCC.

The ideal dashboard can now be characterized in terms of the hardware requirements as well as the visual display properties of the user interface described above. The following items, which include some notable requirements described by St. Germain (2015), will influence the overall design of the dashboard: 
- The size and number of monitors must be determined, based upon an analysis of tasks, workflow and physical work spaces.

- The design of the user interface must follow well-established human factors and visual communication guidelines, as described above.

- The amount of information that it displays must not be overwhelming.

- Each item of information must be displayed in a way that can be quickly examined to assess outage performance, both in terms of an appropriate graphical medium and direct measure of performance (for example, percentage off target).

- Measures must be expressed with enough context (for example, comparisons to targets, averages, and previous periods) for their meanings to be clear.

- Color must be used sparingly and only highlights used for salient items, so that it is easy to spot those items that require attention by, for example, scanning for red.

- The most important items (e.g., the set of KPIs) must be placed in a prominent position of the screen.

- Although the dashboard alerts the person using it to problems or opportunities for optimization, it must not automate a response, but require human intelligence to be engaged in the process and initiate responses.

- Responses must be made easily, such as by clicking on the name of an OCC member who is experiencing difficulty to send an instant message. Because the information can be updated frequently (hours, minutes, or even seconds), when a close examination is desired, updates could be temporarily halted to remove the distraction of changing data.

- Only what is necessary must appear on the dashboard. It must not be cluttered or distractingly decorated. It should not need any instructions for how to use it.

Any additional requirements must be determined through a functional requirements analysis, task analysis, and careful consideration of usability requirements, in terms of guidance provided by ISO 924111.

These criteria can be reduced to a simple framework that helps to identify the required items.

For each item the following questions must be answered positively:

1. Can the information be displayed in a way that makes it actionable? (e.g., does the metric go up, down, flat or off-target and is the required action obvious?)

2. Does the item ensure common interpretation? (i.e., will all team members recognize what this metric means?)

3. Is the metric source transparent? (i.e., how was the metric derived?)

4. Are the data accessible and credible? (i.e., can data be acquired with modest effort from a source that people trust?)

Since all information items indicated above are quantitative in nature, it will be possible to use a combination of the following graphical representations:

1. Bullet graphs (vertical or horizontal) - for parameters that can be tracked for planned and actual performance against measures such as "below expectation, acceptable, exceed expectation".

2. Line graphs - for measures that have a temporal component, i.e., tracked for performance over time.

3. Histograms - for parameters with a volume or quantity component. 
4. Bar graphs with markers for targets and limits - for parameters showing variable quantities (speed, volume, count, etc.).

5. Heat maps - for parameters that deal with abstract or physical areas of variable concentration (e.g., radiation zones, emergent issues, etc.).

6. Colored flags (icons, symbols or indexes) - for status parameters (e.g., red/yellow/green).

7. Numerical fields - only where discrete values are important. These may be in the form of a table.

8. Alerts - to indicate parameters that exceed a threshold (similar to type 6 above).

\subsection{Development of a Prototype Outage Dashboard}

All options for the selection of appropriate data and display features were reviewed to establish the basis for a prototype dashboard. A set of historical outage schedule data as well as data from a current outage was obtained from Palo Verde Nuclear Generating Station (PVNGS) and analyzed to serve as basis for the demonstration of a realistic display of outage information.

The outage schedule data were imported into in Excel and formatted to test a variety of possible representations. Several iterations were evaluated until a version was selected that incorporated the most of the principles and features described above. This version became a template for the development of a functional prototype developed in Microsoft Visual Studio (Windows Presentation Foundation). The result is shown below (Figure 2):

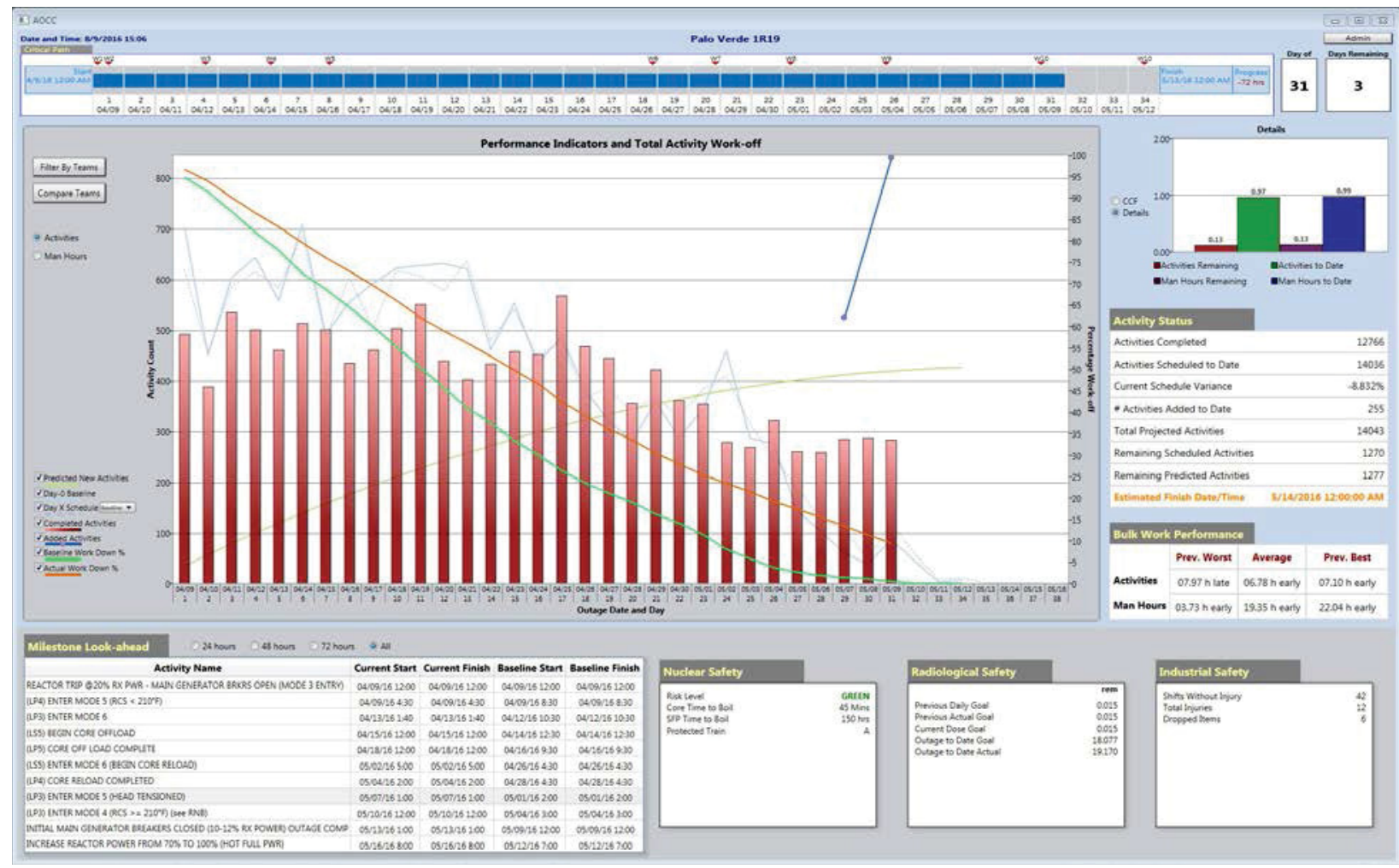

Figure 2: Outage Information Dashboard Prototype (Activity view) 


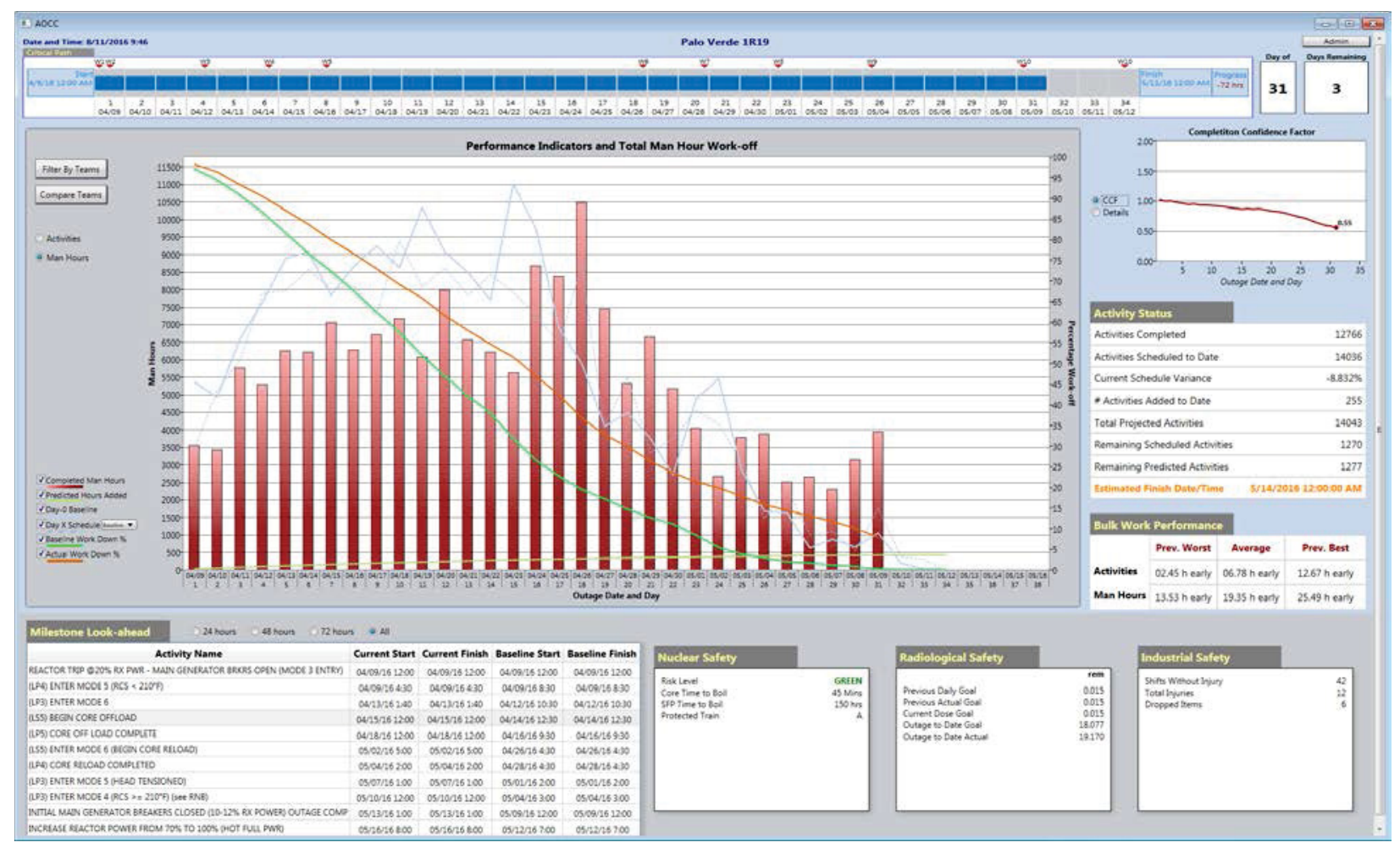

Figure 3: Dashboard Prototype (Man hours view)

Key components of the dashboard as described briefly:

1. Critical path: this is a graphical representation of the overall schedule critical path, rolled up into a single graph with markers for the scheduled work windows. The same graph also shows the outage start date, planned finish date, number of days ahead or behind schedule, current day of the schedule, and number of days remaining.

2. Outage performance chart: This is a combined, multivariate chart displaying the following graphs (optionally selectable):

- Day 0 baseline activity plan

- Baseline work down percentage

- Actual work down percentage

- Completed activities

- Added activities to date

- Predicted new activities

- Day X schedule

The chart can be switched to a similar display, showing man hours instead of activity counts (Figure 3)

3. Activity Status: this is a list of key performance indicators showing activity status to date:

- Activities Completed: The total number of activities completed according to the currently loaded schedule. This is determined by whether there is an Actual End date specified.

- Activities Scheduled to Date: The total number of activities scheduled according to the currently loaded scheduled. This is determined by the number activities subtracted by an excluded activities (Milestones, etc.) 
- Current Schedule Variance: This is the Actual Work down percentage on the current schedule date subtracted by the Baseline Work down percentage on the current schedule date.

- Number of Activities Added to Date: This is the total scheduled activities (according the current schedule) subtracted by the total scheduled activities (according to the day- 0 schedule).

- Total Projected Activities: This is the total scheduled activities (according to the current schedule) plus the cumulative number of predicted new activities on the current schedule's date.

- Remaining Scheduled Activities: This is the total scheduled activities (according to the current schedule) subtracted by the total number of completed activities (according to the current schedule).

- Remaining Predicted Activities: This is the total projected activities subtracted by the total number of completed activities (according to the current schedule).

- Estimated Finish Date: This is calculated by determining the number of days historically it would take to complete the remaining number of activities for the current schedule.

4. Bulk Work Performance: this indicates historical, current and predicted bulk work completion information:

- Previous Worst - this is the number of hours from the target finish date that the current outage is expected to complete according to the "worst" historical outage data (worst is the outage with the latest estimated finish date).

- Previous Best - the number of hours from the target finish date that the current outage is expected to complete according to the "best" historical outage data (best is the outage with the earliest estimated finish date).

- Average - the number of hours from the target finish date that the current outage is expected to complete according to the "average" historical outage data (average is calculated by the average of all the average per day data from every historical outage that is loaded).

An optional pop-up panel (not shown in the example above) shows more detail about activities per day and man hours per day for the best, average, and worst historical outages.

5. Completion Confidence Factor (CCF) - this innovative chart provides a predictive indication of confidence that the outage will finish within the scheduled time frame. It is based upon the following variables, shown in a line graph of the change in CCF over time (see Figure 3). Optional details are also available in a simple histogram (Figure 2) as follows:

- Activities Remaining: This is the total number of scheduled activities subtracted from the total number of completed activities according to the Historical Average Data, divided by the same values as before, but using the current schedule data.

- Activities to Date: the total number of completed activities according to the current schedule data, divided by the total number of completed activities according to the historical averages data.

- Man Hours Remaining: the total number of scheduled man hours subtracted from the total number of completed man hours according to the Historical Average data, divided by the same values as before, but using the current schedule data.

- Man Hours to Date: the total number of completed man hours according to the current schedule, divided by the total number of completed man hours according to the historical average data.

6. General outage information - these are four tables consisting of the following information: 
- Milestone Look-ahead: a list of milestone activities, selectable for a 24 hour, 48 hour, or 72 hour period, or all currently remaining milestones. (This list is imported into the dashboard automatically from the P6 schedule).

- Nuclear Safety: this is a list of items including the current risk level, the current core time to boil, spent fuel pool time to boil, and the current protected train. (This list is updated manually two or three times per day))

- Radiological safety: a list of current radiological exposure measures and goals. (Updated manually two or three times per day)).

- Industrial safety: a list indicating injuries and dropped items to date. (Updated manually two or three times per day).

7. General dashboard management functions: these are user interface management functions that allow the user to configure the display of information:

\begin{tabular}{|c|c|c|}
\hline Item & Purpose & Object(s) \\
\hline Outage identification & $\begin{array}{l}\text { Includes the name and number } \\
\text { of the current outage, as well } \\
\text { as the current date and time. }\end{array}$ & $\begin{array}{c}\text { Date and Time: 8/11/2016 10:06 } \\
\text { Palo Verde 1R19 }\end{array}$ \\
\hline Administrative functions & $\begin{array}{l}\text { Allow the user to load } \\
\text { historical and current schedule } \\
\text { files, and to edit the } \\
\text { information in the general } \\
\text { outage information tables. }\end{array}$ & \begin{tabular}{|l|} 
Administrative Options \\
Select Historical Outages \\
\begin{tabular}{|c|} 
Select Historical Outages \\
Select Milestones \\
Select Milestones to Display \\
Edit Displayed Table \\
Nuclear Safety Status \\
Industrial Safety Status \\
Radiological Safety \\
Select Schedule Files \\
Add Historical Outage \\
Load Day 0 \\
Load Schedule \\
\end{tabular} \\
\end{tabular} \\
\hline Filter by teams button & $\begin{array}{l}\text { Allows filtering of the outage } \\
\text { chart by team. Any number of } \\
\text { teams or all teams can be } \\
\text { selected from a list and the } \\
\text { results observed in the chart. }\end{array}$ & Filter By Teams \\
\hline Compare teams button & $\begin{array}{l}\text { Allows comparison of team } \\
\text { performance - this shows a } \\
\text { pop-up chart that provides } \\
\text { detail information on team } \\
\text { performance for the current } \\
\text { and historical outages per work } \\
\text { window. This display outage } \\
\text { personnel to determine relative }\end{array}$ & Compare Teams \\
\hline
\end{tabular}




\begin{tabular}{|c|c|c|}
\hline & $\begin{array}{l}\text { performance of teams and } \\
\text { make decisions regarding } \\
\text { resource requirements and } \\
\text { allocation. }\end{array}$ & \\
\hline Activity/Man hours toggle & $\begin{array}{l}\text { Allows user to switch between } \\
\text { display of Activities and Man } \\
\text { hours. }\end{array}$ & $\begin{array}{l}\text { Activities } \\
\text { Man Hours }\end{array}$ \\
\hline Chart Variable Checkboxes & $\begin{array}{l}\text { Allow the user to turn on or off } \\
\text { specific variables in the outage } \\
\text { chart. }\end{array}$ & $\begin{array}{l}\text { V Predicted New Activities } \\
\text { VDay-0 Baseline } \\
\text { VDay X Schedule Baseline - } \\
\text { V Completed Activities } \\
\text { VAdded Activities } \\
\nabla \text { Baseline Work Down \% } \\
\nabla \text { Actual Work Down \% }\end{array}$ \\
\hline
\end{tabular}

\subsection{Application of the PSF to the Palo Verde Dashboard}

The prototype described above has been tested by the INL AOCC project team and discussed in general terms with outage staff at PVNGS and other utilities. In preparation for a more extensive evaluation, the PSF framework described before was applied to the prototype as a way to determine to what extent it conforms to a coherent semantic architecture suitable to this kind of dashboards. The analysis of the semantic and syntactic architecture of the prototype follows the example in Table 2. This helped the project team to assess the extent to which the prototype conforms to the basic precepts of good visual communication. It should be emphasized however that, as a prototype, it has not yet been tested under actual outage conditions. It also has not yet been subjected to a full usability evaluation. Until this is done, it will not be possible to validate it for semiotic adequacy. The prototype should be tested during Palo Verdes Fall 2016 refueling outage. After the outage, staff will be interviewed and modifications to the dashboard will be made if necessary. 
Table 3: PSF Analysis of a Conceptual AOCC Dashboard

\begin{tabular}{|c|c|c|c|c|c|}
\hline \multirow[b]{2}{*}{$\begin{array}{l}\text { Horizontal } \\
\text { Syntagms }\end{array}$} & \multicolumn{2}{|c|}{ MACRO LEVEL } & \multicolumn{2}{|c|}{ MESO LEVEL } & \multirow{2}{*}{$\begin{array}{l}\text { MICRO LEVEL } \\
\text { Discrete Signs } \\
\text { (DS) }\end{array}$} \\
\hline & $\begin{array}{c}\text { Physical Interaction } \\
\text { System } \\
\text { (PS) }\end{array}$ & $\begin{array}{l}\text { Subject Matter } \\
\text { (SM) }\end{array}$ & $\begin{array}{c}\text { Spatial organization } \\
\text { (SO) }\end{array}$ & $\begin{array}{l}\text { Figurative screen } \\
\text { image } \\
\text { (FI) }\end{array}$ & \\
\hline & $\begin{array}{l}\text { A. Computer Hardware: } \\
\text { LCD wide panel displays, } \\
\text { keyboards, mouse, printers, } \\
\text { buttons }\end{array}$ & $\begin{array}{l}\text { A. Category: Nuclear } \\
\text { Generating Station Outage } \\
\text { Management }\end{array}$ & $\begin{array}{l}\text { A. 2-Dimensional field: } \\
\text { Functional and organizational } \\
\text { representation of outage } \\
\text { status and key performance } \\
\text { indicators }\end{array}$ & $\begin{array}{l}\text { A. Size, brightness, resolution: } \\
\text { AOCC displays are } 60 \text { inch } \\
\text { LCD panels at } 2560 \times 1600 \\
\text { pixels. Displays are spatially } \\
\text { dedicated, continuously visible } \\
\text { (SDCV) }\end{array}$ & $\begin{array}{l}\text { A. Shapes \& forms: } \\
\text { - Graphs } \\
\text { - Graphical critical path } \\
\text { - Information pop-ups } \\
\text { - Display control buttons } \\
\text { (dashboard setup and } \\
\text { navigation) }\end{array}$ \\
\hline & $\begin{array}{l}\text { B. Software: Operating } \\
\text { system, User Interface } \\
\text { Management System, } \\
\text { database }\end{array}$ & $\begin{array}{l}\text { B. Data organization: } \\
\text { Moderately complex and } \\
\text { abstract data relationships } \\
\text { Level of subject matter } \\
\text { complexity: High - requires } \\
\text { considerable experience } \\
\text { and training }\end{array}$ & $\begin{array}{l}\text { B. 3-Dimensional field: None } \\
\text { - physical appearance and } \\
\text { spatial relationships of } \\
\text { information on 2-D field only }\end{array}$ & $\begin{array}{l}\text { B. Color: used to convey } \\
\text { specific information (e.g. to } \\
\text { differentiate between outage } \\
\text { events and characteristics) and } \\
\text { to categorize graphic } \\
\text { elements. Within the limitation } \\
\text { of maximum } 7 \text { colors per } \\
\text { display, standardized color is } \\
\text { also used to indicate interface } \\
\text { backgrounds, functional areas } \\
\text { and objects. }\end{array}$ & $\begin{array}{l}\text { B. Icons: None in current } \\
\text { version }\end{array}$ \\
\hline 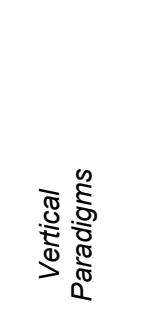 & $\begin{array}{l}\text { C. Environment: OCC room } \\
\text { structure, consoles, desks, } \\
\text { communication equipment, } \\
\text { storage, seating, lighting, } \\
\text { etc. }\end{array}$ & $\begin{array}{l}\text { C. Combination of graphic, } \\
\text { symbolic, textual }\end{array}$ & $\begin{array}{l}\text { C. 4-Dimensional Field } \\
\text { (Temporal dimension): } \\
\text { Change of graph lines over } \\
\text { time, KPI value change }\end{array}$ & $\begin{array}{l}\text { C. Level of realism/abstraction: } \\
\text { Top levels of the dashboard } \\
\text { employ abstract metaphors } \\
\text { (e.g. graphical representation } \\
\text { of data value change over } \\
\text { time) and lower levels employ } \\
\text { more concrete metaphors } \\
\text { (textual) to represent outage, } \\
\text { schedule status, and resource } \\
\text { information. }\end{array}$ & $\begin{array}{l}\text { C. Symbols: Graphical } \\
\text { rectangles (histogram bars), } \\
\text { solid and broken lines of } \\
\text { different thicknesses, triangles } \\
\text { (work windows) }\end{array}$ \\
\hline
\end{tabular}




\begin{tabular}{|c|c|c|c|}
\hline & $\begin{array}{l}\text { D. Concrete: none } \\
\text { Abstract: outage status, } \\
\text { key performance indicators, } \\
\text { schedule, and resource } \\
\text { information }\end{array}$ & $\begin{array}{l}\text { D. Composition, layout, image } \\
\text { complexity: Composition and } \\
\text { layout follow the outage crew } \\
\text { member's natural task flow. } \\
\text { Graph and information layouts } \\
\text { are kept as simple as possible } \\
\text { to avoid ambiguity and visual } \\
\text { noise. }\end{array}$ & $\begin{array}{l}\text { D. Indexes: outage } \\
\text { performance trend graph, } \\
\text { numerical values, relative } \\
\text { position of outage graphical } \\
\text { data. }\end{array}$ \\
\hline Signifier level & \multicolumn{3}{|c|}{$\begin{array}{l}\text { Spatiality: schedule and KPI objects and signs are not arranged on the display to correspond to the spatial layout of the plant or the location of any resource, but } \\
\text { to reflect the status and temporal progression of the outage process. } \\
\text { Contrast: active schedule objects (e.g. completed activities) are highlighted to achieve the highest possible contrast with the display background. Inactive objects } \\
\text { (e.g. Day-0 Baseline graph) are displayed with lower contrast so that staff can focus on active objects. } \\
\text { Shape: Objects are either represented as stylized, recognizable forms (solid or broken lines and histograms) or as abstract symbols (work window symbols, etc.) } \\
\text { Color: Graphical outage progress and status data are color coded. Colors used on the dashboard are generally limited to } 7, \text { corresponding to the number of } \\
\text { variables that can be displayed at any time. Backgrounds are consistently dark grey (RGB 128,128,128). } \\
\text { Texture: This is generally avoided in the dashboard to avoid visual noise. } \\
\text { Metaphor: The predominant metaphor employed in the dashboard is the graphical representation of temporal progression of a number of variables. Since no } \\
\text { physical or concrete representations are used, no ecological relationships (i.e. spatial relationships between physical entities) are included in the metaphor. All } \\
\text { other metaphors are abstract textual representations of outage status. }\end{array}$} \\
\hline Signification level & \multicolumn{3}{|c|}{$\begin{array}{l}\text { Connotative \& Denotative content: } \\
\text { Arbitrary Signs: } \\
\text { - abstract symbols for work windows and outage status and processes } \\
\text { - trend graphs to indicate real-time value of outage variables } \\
\text { - text, diagrams, graphs to represent plant safety and outage performance and status } \\
\text { - digital indicators (numeric values \& labels) of outage status } \\
\text { Figurative representations (object schemata): } \\
\text { - no realistic or semi-realistic images are employed in the dashboard } \\
\text { - analogue representations are limited to the temporal values of outage variables } \\
\text { Logical, cognitive or denotative content: } \\
\text { Graphical and textual representations on the dashboard are recognized as abstract outage process, status and performance indicators } \\
\text { Connotative or associative meaning: } \\
\text { Example: a specific shape of the outage graph (e.g. an extraordinary peak in the dark blue line is associated with a significant amount of activities added to the } \\
\text { work scope, or an actual work down graph that is significantly higher than the baseline work down graph is associated with outage performance that is poorer } \\
\text { than expected. } \\
\text { Stylistic meaning (layout, context, etc.): } \\
\text { Example, the spatial relationship between simultaneous representations of different outage variables indicates a possible comparison between planned and } \\
\text { actual values at the same point on the time line. }\end{array}$} \\
\hline & \multicolumn{3}{|c|}{$\begin{array}{l}\text { 1. Physical Interaction System is expressed by the paradigms of computer and display hardware, software and physical environment within which the outage } \\
\text { crew member performs his tasks. }\end{array}$} \\
\hline
\end{tabular}




\begin{tabular}{|l|l|}
\cline { 2 - 2 } & $\begin{array}{l}\text { 2. Subject Matter is expressed by the paradigm of nuclear power station outage management with a high complexity, employing a combination of textual, } \\
\text { graphical and symbolic information representation, ranging from concrete to abstract. }\end{array}$ \\
\hline $\begin{array}{l}\text { 3. Spatial organization is expressed by the paradigm of the 2-dimensional layout of the dashboard (emphasis on SDCV), and the indication of dynamic } \\
\text { changes of variables over time during the execution of the outage. }\end{array}$ & $\begin{array}{l}\text { 4. The figurative screen image is constructed from the paradigms of size, brightness, resolution, color, level of realism or abstraction, and composition and } \\
\text { layout of outage graphical and textual objects. }\end{array}$ \\
\hline $\begin{array}{l}\text { 5. Discrete signs in the interface are constructed from the paradigms of shape and form, icons, symbols and indexes used to distinguish outage variables and } \\
\text { information. }\end{array}$ & $\begin{array}{l}\text { Meaning is thus represented at three levels: } \\
\text { Individual } \\
\text { syntagm: }\end{array}$ \\
$\begin{array}{l}\text { - The "frame message" by the vertical paradigms that form the } 5 \text { syntagms. } \\
\text { Denotative meaning at the figurative level is represented by the signifiers of spatiality, contrast, shape, color, texture and metaphor. }\end{array}$ \\
\hline
\end{tabular}


The analysis above suggests that that the visual structure of a dashboard like this can serve as a primary source of outage information for OCC team members. Its visual architecture also seems adequate as a navigational mechanism for users. Dashboard content and appearance has been organized in a way that reflects the nature of the information and that supports efficient and meaningful monitoring of outage status.

Further investigation is necessary to determine optimal placement and size of information segments. Special attention must be paid to visual and cognitive saliency. In other words, does the relative prominence of an information item encourage rapid perception, reduced need for information search, and improved decision making?

Further evaluation must also verify the adequacy of these elements:

1. Information design - selection, classification and validation of information elements

2. Graphic design - selection, semiotic evaluation and design of graph types to match information types

3. Interface design - layout, typography, color, and semiotics

4. Interaction design - selection and design of navigation schemes and interactive features

5. Usability testing - ensuring that specific users are able to use the dashboard with effectiveness, efficiency, and satisfaction in defined contexts

In summary, key considerations for the dashboard that must be verified include the following:

- Timeliness: How frequently will the data in the dashboard be updated?

- Aesthetic value: How important is it that the dashboard looks attractive, or can it be purely utilitarian?

- Mobility: Do users need to access the information on the go? In which case, can the dashboard and/or some or all of its contents be disseminated to portable devices?

- Connectivity: Does the dashboard need to connect to live data sources?

- Data detail: Will the dashboard offer an ability to drill down to see more context?

- Data density: How information-rich do views of the data need to be?

- Interactivity: How will users benefit from interacting with the dashboard?

- Collaboration: Is it important for OCC members to be able to easily share and collaborate on the dashboard?

- Is it necessary for software applications to be embedded in the dashboard display (e.g., Excel, P6, etc.)?

- Does the dashboard need filters to reduce, expand or collapse detail in specific groups?

\section{CONCLUSIONS}

Effective management of NPP refueling outages relies on processing and interpreting enormous volumes of data. This data comes from numerous sources, with schedule data being the largest and arguably most important data source to analyze. Schedule data can be considered by breaking the problem into two distinct management challenges: critical path and bulk work. Critical path, while important, is much easier to visualize, track and manage. Bulk work, which is comprised of the thousands of activities not on critical path, is much more challenging to manage. The techniques used to manage critical path activities would be too labor intensive to apply to all bulk work. Additional tools are required to allow 
bulk work to be managed with fewer resources from the OCC. Previous AOCC pilot project reports have provided information on OCC physical design, technology tools for improving emergent issue resolution, technologies and techniques for making outage information visible and sharable as well as new ways for displaying schedule information to take advantage of capabilities enabled by the use of electronic work packages. This report focuses on tools that utilize technology to improve the outage manager's understanding of the true outage status. The primary tool described in this report is an interactive dashboard with built in data analysis capabilities. The dashboard takes advantage of data visualization techniques that allow the human brain to process information more efficiently when presented in different forms. Additionally, the dashboard incorporates historical performance data to help outage managers compare current productivity with previous outage productivity. This new dashboard concept not only presents information, but also attempts to predict the completion of the current outage using data analysis of the current schedule and historical performance of the NPP. This report describes the science behind information presentation and dashboard design and describes in detail a prototype dashboard software application developed by the AOCC pilot project team. This software application will be available in the near future for use by nuclear power plants to assist in presenting and understanding true outage status.

\section{REFERENCES}

[1] Andersen, P. B. (2006). A Theory of Computer Semiotics. Cambridge University Press.

[2] Barr, P., Biddle, R., \& Noble, J. (2005). A Semiotic Model of User-Interface Metaphor. In K. Liu (Ed.), Virtual, Distributed and Flexible Organisations: Studies in Organisational Semiotics (pp. 189-215). Dordrecht: Springer Netherlands.

[3] Bedny, G. \& Karwowski, W. (2004). Meaning and sense in activity theory and their role in the study of human performance. International Journal of Ergonomics and Human Factors. 26:2, 121-140.

[4] Chandler, D. (2007). Semiotics: The Basics (2nd ed.). London: Routledge.

[5] de Souza, C.S. (2005). The Semiotic Engineering of Human-Computer Interaction. The MIT Press.

[6] Dekker, S. \& Hollnagel, E. (2004). Human Factors and folk models. Cognition, Technology and Work, 6:2, 79-86.

[7] Endsley, M., Bolte, D. \& Jones, D. (2003). Designing for Situation Awareness: An Approach to User-Centered Design. CRC Press: Boca Raton.

[8] Few, S. (2009). Now You See It: Simple Visualization Techniques for Quantitative Analysis. Burlingame, CA: Analytics Press.

[9] Goguen, J. (1999). An Introduction to Algebraic Semiotics, with Application to User Interface Design. Springer.

[10] Goguen, J. (2000). Semiotic Morphisms. Retrieved January 14, 2005 from http://wwwcse.ucsd.edu/users/goguen/papers/sm/node5.html

[11] Hugo, J. (1992). Computer-mediated Visual Communication: A Visual Literacy Perspective. Masters Thesis. University of South Africa, Pretoria, South Africa.

[12] Hugo, J. (2005). The Semiotics of Control Room Situation Awareness. In Thatcher, A., J. James, \& A. Todd (Eds.), CybErg 2005 (pp. 1-14). Johannesburg, South Africa: International Ergonomics Association Press. 
[13] Hugo, J., and Gertman, D. (2013). A Qualitative Method to Estimate HSI Complexity. Nuclear Engineering and Technology, 45(2), 10.

[14] Keim, D., Kohlhammer, J., Ellis, G. and Mansmann, F. (Eds.) (2010). Mastering the Information Age - Solving Problems with Visual Analytics. Retrieved from Eurographics Digital Library, http://diglib.eg.org

[15] Lotman, J.M. (1990). The Semiosphere. Zeitschrift für Semiotik. The Research Centre for Semiotics, 1990, 12:4.

[16] Parasuraman, R., \& Mouloua, M. (1996). Automation and Human Performance: Theory and Applications (Human Factors in Transportation). Mahwah, NJ: CRC Press.

[17] Sheridan, T. B. (2002). Humans and Automation: System Design and Research Issues. Santa Monica, CA: Wiley-Interscience.

[18] St. Germain, S., et. al. (2014). Guidelines for Implementation of an Advanced Outage Control Center to Improve Outage Coordination, Problem Resolution, and Outage Risk Management. INL/EXT-14-33182. Idaho National Laboratory: Idaho Falls, ID.

[19] St. Germain, S., Farris, R. and Thomas, K. (2015). Development of Improved Graphical Displays for an Advanced Outage Control Center, Employing Human Factors Principles for Outage Schedule Management. INL/EXT-15-36489. Idaho National Laboratory: Idaho Falls, ID.

[20] Tufte, E. R. (2001). The Visual Display of Quantitative Information (2nd ed.). Cheshire, CT: Graphics Press.

[21] Wickens, C.D, J.D. Lee, Y. Liu, and S.E.G. Becker, (2004). An Introduction to Human Factors Engineering, Second Edition, Upper Saddle River, NJ: Prentice Hall. 